\title{
Determination of Rain Cell Characteristics from the Analysis of TOPEX Altimeter Echo Waveforms
}

\author{
JEAN TOURnADRE \\ Institut Français de Recherche pour l'Exploitation de la Mer, Centre de Brest, Plouzane, France
}

(Manuscript received 26 August 1996, in final form 13 June 1997)

\section{ABSTRACT}

\begin{abstract}
Radar meteorologists have estimated, over a number of years, rainfall rate with ground-based radars. Since the 1970s, use of weather radar as an active technique to measure rainfall from space has been proposed, and a number of radar concepts, including modified radar altimeter design, were proposed. However, no attempt has yet been made to determine rain cell characteristics from available altimeter data. This paper presents a method to estimate rainfall rate and rain cell diameter from TOPEX/Poseidon dual frequency radar altimeter waveforms. The rain-affected waveforms are first selected using a criterion based on a departure from a normal $\mathrm{Ku}-\mathrm{C}$-band backscatter coefficient relationship and on a threshold of liquid water content estimated by the TOPEX microwave radiometer. The analytical representation of echo waveforms under rain conditions is used to model the effect of rain. A minimization procedure is then used to determine the model's best fit to the observed waveforms. Several case studies are presented to illustrate the method. These cases include squall lines, isolated light rain cells, and a tropical cyclone. The method, shown to give a high-resolution description of the rain distribution under various weather conditions, could be used to obtain global rain cell characteristics over the ocean.
\end{abstract}

\section{Introduction}

Since the launch of Seasat, the observation of anomalously high winds obtained with unusually low values of the backscatter coefficient $\sigma_{0}$ on the altimeter echo plateau when the satellite passed over storms has led to investigate the effects of rain on the echo (SEASAT 1979). Subsequently, several studies have been published on both the theoretical and practical aspects of the influence of rain on altimeter data. The main purpose of these studies was to determine the uncertainties on geophysical quantities such as sea surface height, significant wave height, and wind speed, inferred from altimeter data (Walsh et al. 1984; Barrick and Lipa 1985; Monaldo et al. 1986). As no reliable correction can presently be made for the whole range of geophysical parameters, the strategy adopted in altimeter data processing has been to flag possible occurrences of rain. The flags are either based on concurrent passive microwave radiometer measurements or, more recently, for the dual frequency NASA radar altimeter (NRA) on board the TOPEX/Poseidon satellite, on a departure from a normal $\mathrm{Ku}$ - and $\mathrm{C}$-band backscatter coefficient (Morland 1994; Quartly et al. 1996; Tournadre and Morland 1998).

Corresponding author address: Dr. Jean Tournadre, IFREMER, DRO-OS BP, 7029280 Plouzané, France.

E-mail: jeant@ifremer.fr
Different authors also proposed to modify altimeter design to measure rain-rate profiles (Goldhirsh 1983; Goldhirsh and Walsh 1982; Goldhirsh 1988; Testud et al. 1992; Testud et al. 1996). The new design proposes the incorporation in the altimeter radar system of a new mode during which no range data are gathered, but rain backscatter measurements are collected using unmodulated continuous wave pulses during $50 \mathrm{~ms}$ every second of altimeter operations.

Analysis of Ku-band ERS-1 radar altimeter waveforms during rain events (Guymer et al. 1995) showed a good agreement between the observed waveforms and the ones predicted by the theory developed by Barrick and Lipa (1985). However, no attempt has yet been made to infer rain cell characteristics (size, rainfall rate, etc.) from waveform analysis. Considering the good quality of TOPEX Ku-band waveform data (Hayne et al. 1994) and the fact that the theoretical approach of rain effects on echo waveforms appears mature, we examined the possibility of determining rain cell characteristics from the analysis of waveforms. The waveforms possibly affected by rain are first detected using the criterion based on Ku- and C-band $\sigma_{0}$ 's defined by Quartly et al. (1996) and Tournadre and Morland (1998) and then analyzed in terms of rain cells.

A brief description of the NRA altimeter data and echo waveform is given in section 2 . The effects of rain on altimeter waveforms and the model used in this study are presented in section 3, as well as the criteria used 
to detect rain-affected altimeter samples. Section 4 describes the method used to determine rain cells characteristics from the analysis of waveforms. Cases studies illustrating different situations are given in section 5 . Finally, the conclusions of this study are presented.

\section{TOPEX/Poseidon altimeter data}

The TOPEX/Poseidon satellite, developed by the National Aeronautics and Space Administration (NASA) and the French Space Agency (CNES) was launched on 10 August 1992. TOPEX/Poseidon is dedicated to ocean altimetry: the orbit, satellite bus, and payload are optimized to map the ocean surface. The satellite carries two altimeters: one developed by CNES and the other by NASA. The single-frequency solid-state altimeter developed by CNES, an experimental instrument intended to demonstrate a new technology, operates approximately $10 \%$ of the time. The NRA altimeter, which operates at $13.6 \mathrm{GHz}$ ( $\mathrm{Ku}$ band) and $5.3 \mathrm{GHz}$ (C band) simultaneously, is the primary sensor of the mission. Only the dual-frequency NRA data will be considered in this study.

The NRA antenna is a $1.5-\mathrm{m}$-diameter parabolic reflector. The beamwidth of this antenna, $1.1^{\circ}$ for $\mathrm{Ku}$ band and $2.7^{\circ}$ for $\mathrm{C}$ band, covers an area on the surface of $20 \mathrm{~km}$ for $\mathrm{Ku}$ band and $50 \mathrm{~km}$ for $\mathrm{C}$ band. The pulse limited operation of the system restricts the width of the footprint to about $20 \mathrm{~km}$ for a flat sea surface at gate 128 for both frequencies. The NRA emits radar pulses at a rate of $4500 \mathrm{~Hz}$ in $\mathrm{Ku}$ band and $1200 \mathrm{~Hz}$ in $\mathrm{C}$ band (Zieger et al. 1991; Marth et al. 1993). The received pulses are deramped to remove the linear FM and processed by frequency filtering to form waveforms, each consisting of 128 samples of the power backscatter from a particular range. The $320-\mathrm{MHz}$ pulse bandwidth results in a sample resolution of $0.47 \mathrm{~m}$ (corresponding to a two-way travel of $3.125 \mathrm{~ns}$ ). The waveforms received after reflection from the surface and transmission through the atmosphere are averaged on board in groups of 228 in the $\mathrm{Ku}$ band and 60 in the $\mathrm{C}$ band to minimize the impact of noise. One track interval corresponds to about $53 \mathrm{~ms}$ of data. This is the smallest time interval over which the signal processor of the altimeter interprets the waveforms. It corresponds to a satellite ground track interval of $580 \mathrm{~m}$. The 128 onboard waveforms samplers are then combined (averaged) in multiples of 1,2 , and 4 to form the 64 telemetry samples available in normal track mode used in this study (Hayne et al. 1994).

Based on a functional formulation of the altimeter mean return waveform, the $20-\mathrm{Hz}$ waveforms are interpreted to yield geophysical variables of interest, that is, the travel time of the radar pulse and thus the altimetric height, and the significant wave height (Zieger et al. 1991). The automatic gain control (AGC) of the altimeter is used to calculate the radar cross section $\sigma_{0}$, which is related to the surface wind speed (Chelton and

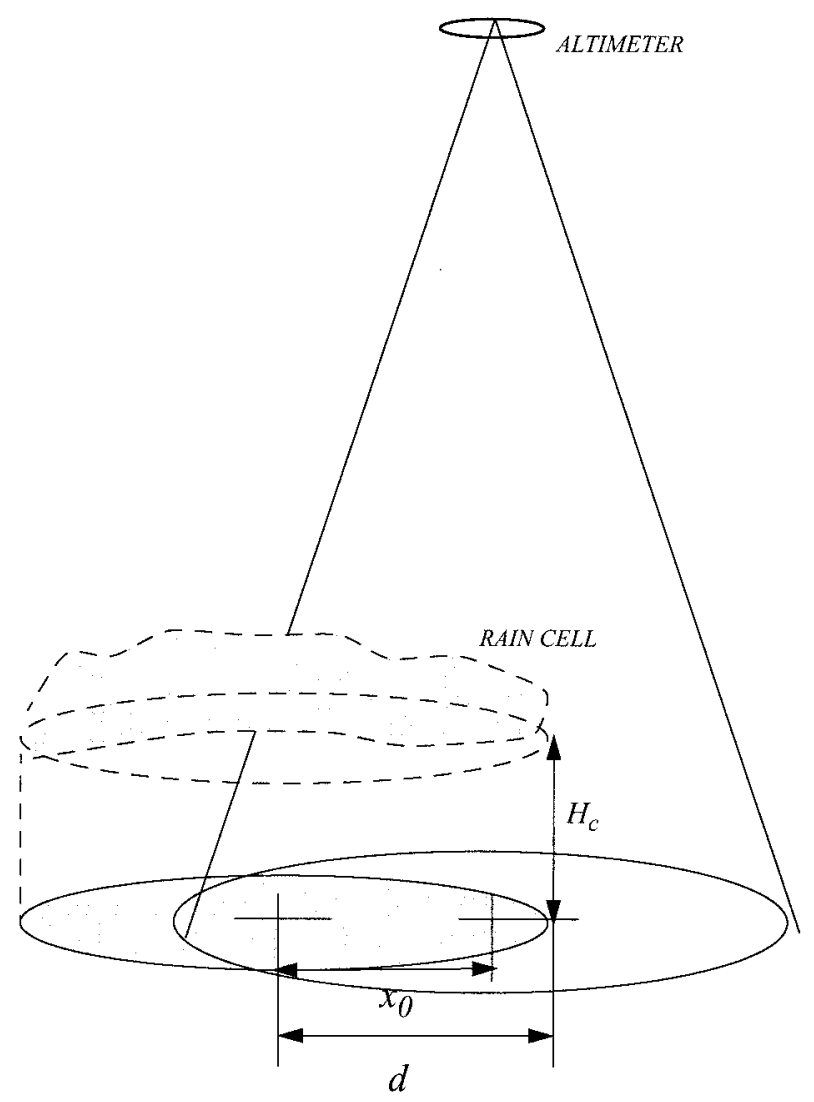

FIG. 1. Model of rain cell geometry.

McCabe 1985). A detailed description of the analysis and interpretation of altimeter sea echo was given in a review paper by Barrick and Lipa (1985).

Each altimeter record contains 20 height, significant wave height, and AGC measurements; 10 64-sample $\mathrm{Ku}$-band waveforms; and 5 64-sample C-band waveforms. The sensor data records (SDRs) used in this study were provided by the NASA/Goddard Space Flight Center, Wallops Flight Facility. The geophysical data records (GDRs) were provided on CD-ROMs by AVISO (AVISO 1992).

After the launch of the satellite, a number of small waveform departures from the model waveforms were found, these waveform "features" are described in detail in Hayne et al. (1994). The waveforms used in this study have been corrected using the correction factors proposed by these authors.

\section{Rain effects on altimeter data}

a. Echo waveforms during rain events

All geophysical variables measured by an altimeter can be affected by rain. A uniform rainfall filling the entire altimeter footprint can, in principle, produce three different possible effects on microwave pulses. First, liquid water alters the refractive index of the atmosphere 

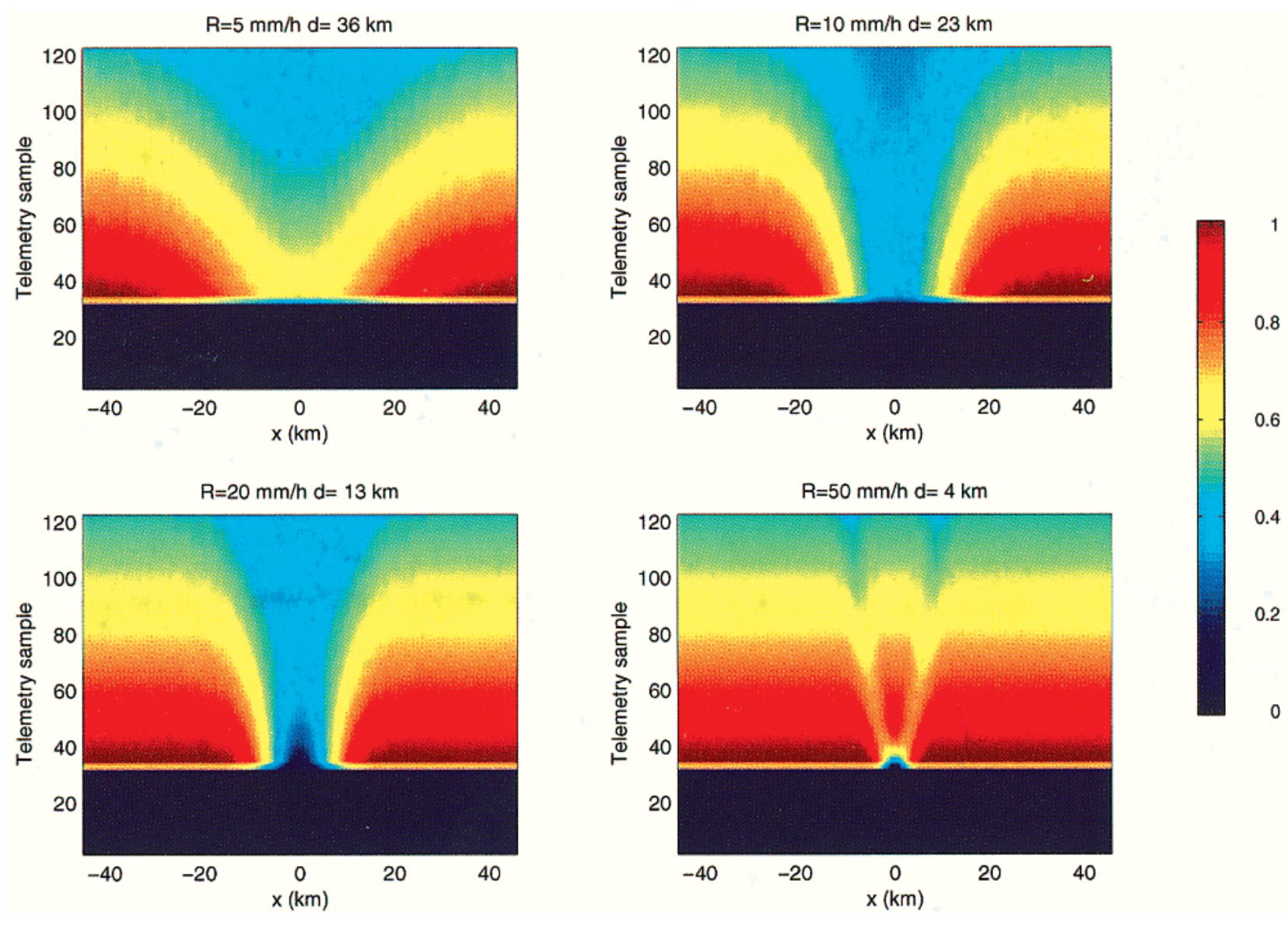

FIG. 2. TOPEX Ku-band altimeter waveforms modeled using relation (3) showing the effect of rain as the altimeter passes over the rain cell for four different rain cells corresponding to light, medium, heavy, and very heavy rainfall. The rms wave height used is $2 \mathrm{~m}$, and the rain cell height is $5 \mathrm{~km}$.

and lowers the velocity at which microwaves propagate through the medium. The arrival of the pulse is thus retarded, artificially increasing the range measurement made by the altimeter. At $\mathrm{Ku}$ - and $\mathrm{C}$-band frequencies the range measurements errors induced by rain can be considered as negligible, except for heavy thunderstorms (Goldhirsh and Rowland 1982). Second, raindrops scatter some of the energy of the incident pulse back to the sensor and thus increase the power backscattered to the altimeter. Scattering is weak at $\mathrm{Ku}-$ and C-band frequencies. The rain echo is four orders of magnitude lower than the sea surface echo, even in a heavy rainfall, and can thus be neglected (Goldhirsh and Rowland 1982). Third, raindrops absorb the altimeter pulse and cause a decrease in the return pulse power. Absorption is the prime contribution of rain to the signal in $\mathrm{Ku}$ and $\mathrm{C}$ bands (Goldhirsh and Rowland 1982). Absorption can reduce the absolute level of the entire altimeter echo strength. This effect is frequency dependent and is more than one order of magnitude less at $\mathrm{C}$ band than at $\mathrm{Ku}$ band (Goldhirsh and Rowland 1982).

Examination of rain cell characteristics reveals that rain might often not uniformly fill the altimeter foot- print. In general, the more intense the rain rate, the smaller the rain cell on average (Goldhirsh 1983). When this occurs, the signal received by the altimeter is distorted. Walsh et al. (1984) and Monaldo et al. (1986) used computer simulations and Barrick and Lipa (1985) analytical representation to compute the altimeter echo return powers for given rain cell dimensions in order to investigate the effect of changing the position of the rain cell relative to the altimeter nadir.

The model developed by Barrick and Lipa (1985), used extensively in this study, is given in detail in appendix A. We considered a circular three-dimensional rain cell model of height $H_{C}$ (see Fig. 1) with the rain rate $R$ defined as

$$
R(x, y)=R_{0} g(\rho),
$$

where $\rho=\left(x^{2}+y^{2}\right)^{1 / 2}$ is the polar distance from the rain cell center $x_{0}, R_{0}$ is the peak rain rate at the surface, and $g(\rho)$ defines the rain-rate falloff normalized to unity at the rain cell center.

Following Goldhirsh and Walsh (1982) and Barrick and Lipa (1985), as well as Testud et al. (1996), a Gaussian shape was chosen for $g$. This is certainly a highly 


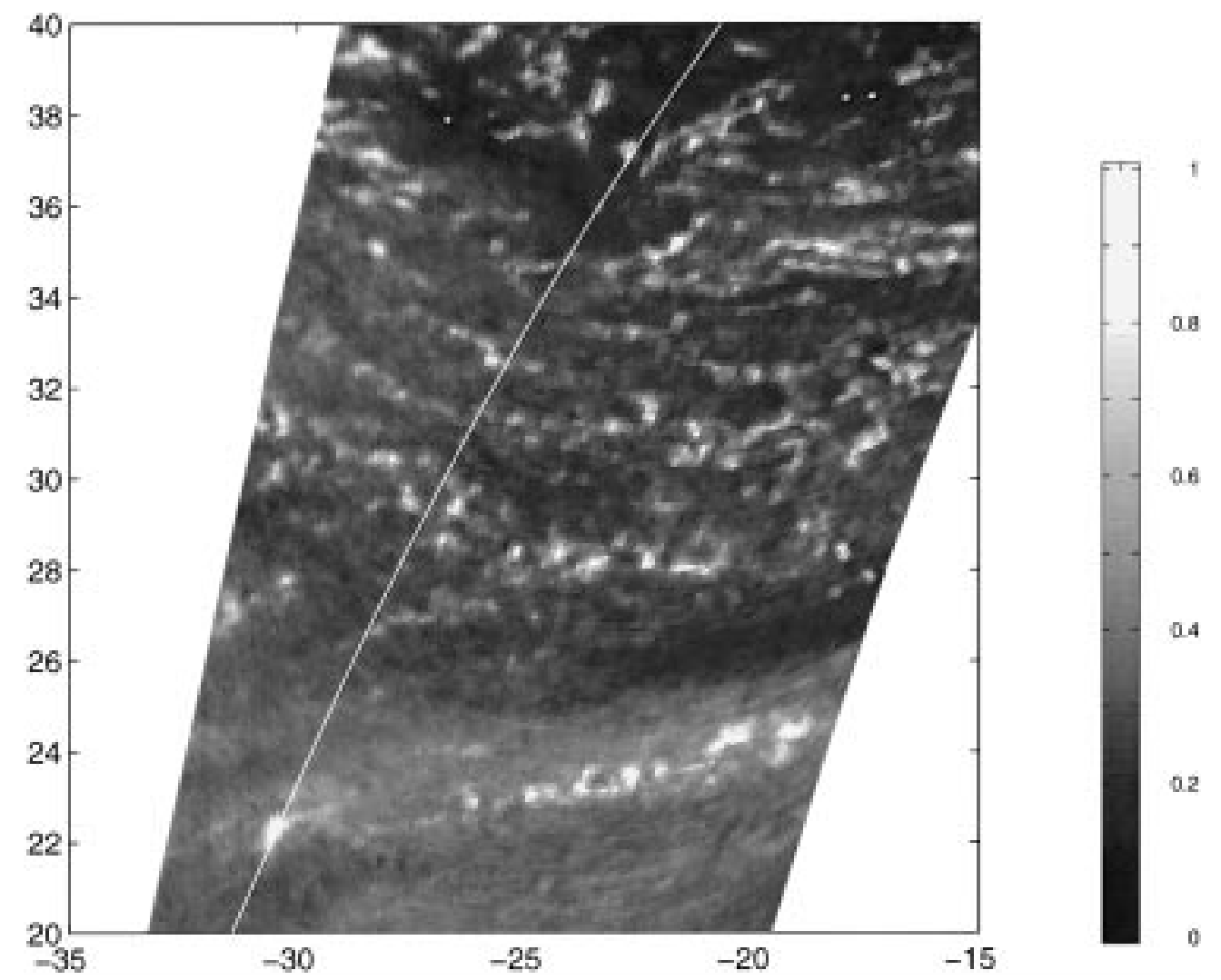

FIG. 3. SSM/I liquid water content, $\mathrm{LW}_{85}\left(\mathrm{~kg} \mathrm{~m}^{-2}\right)$, at 0720 UTC 16 October 1992. The white line represents the TOPEX ground track (cycle 3 pass 87 ) at 0844 UTC the same day.

idealized model for a rain cell, but a study by Capsoni et al. (1987) showed that for a rain rate up to $50 \mathrm{~mm}$ $\mathrm{h}^{-1}$, the Gaussian model fit the radar observations reasonably well. It also allows us to develop an analytical representation of the effect of rain on altimeter echo. Other rain-rate falloffs are considered in appendix A. Here, $g$ is defined by

$$
g(\rho)=\exp \left[-4 \ln 2\left(\frac{\rho}{d}\right)^{2}\right],
$$

where $d$, the rain cell "diameter," corresponds to a rain rate half of the peak rain rate.

Assuming that the joint height-slope probability density of the sea surface is Gaussian, the normalized sea surface echo can be expressed as (see appendix A)

$$
\begin{aligned}
\sigma_{N}\left(\frac{2 x}{c}\right) \\
=\frac{\sigma_{0} \sigma_{\tau}}{\sqrt{2 \pi}}\left[1+\operatorname{erf}\left(\frac{x}{\sqrt{2} \sigma_{p}}\right)\right] e^{-\left(x / u_{b}\right)}+\frac{\sigma_{0} \sigma_{\tau}}{\pi \sigma_{p}} A_{R} e^{-\left(x_{0}^{2} / r^{2}\right)} \\
\quad \times \int_{0}^{\infty} e^{-\left[(u-x)^{2} / 2 \sigma_{p}^{2}\right]-\left(u / u_{b}^{\prime}\right)} I_{o}\left(\frac{2 x_{0} H \psi_{b}}{r^{2}} \sqrt{\frac{u}{u_{b}}}\right) d u
\end{aligned}
$$

where $c$ is the speed of light, erf is the error function, $\sigma_{p}$ is defined as $\sqrt{h^{2}+\sigma_{\tau}}, h$ is the sea surface rms $(\sim \operatorname{swh} / 4), \sigma_{\tau}$ is the compressed pulse standard deviation, and $\sigma_{0}$ is the average normalized backscattering cross section per unit area at normal incidence. Here, $I_{0}$ is the first-order modified Bessel function; $\psi_{b}$ is the antenna half-power beam width $\left(0.4671^{\circ}\right.$ for TOPEX); $u_{b}$ is defined by

$$
u_{b}=\frac{1}{2} H\left(1+\frac{H}{a}\right) \psi_{b}^{2},
$$

where $H$ is the satellite altitude $(1336 \mathrm{~km})$ and $a$ is the earth's radius. Here, $u_{b}^{\prime}$ is defined by

$$
u_{b}^{\prime}=\frac{u_{b}(1+H / a)}{1+\left(2 u_{b} H\right) / r^{2}},
$$

with $r=d /(2 \sqrt{\ln 2})$. The two-way attenuation $A_{R}$ is defined by

$$
A_{R}=10^{-\left(2 k_{p} H_{c}\right) / 10}-1 .
$$

The one-way signal attenuation rate $k_{p}\left(\mathrm{~dB} \mathrm{~km}^{-1}\right)$ due to the rain is related by the Marshall-Palmer (Marshall and Palmer 1948) relationship to the rainfall rate $R$ :

$$
k_{p}=\alpha R_{0}^{\beta} .
$$

At $13.6 \mathrm{GHz}$, the Ku-band operating frequency of the 

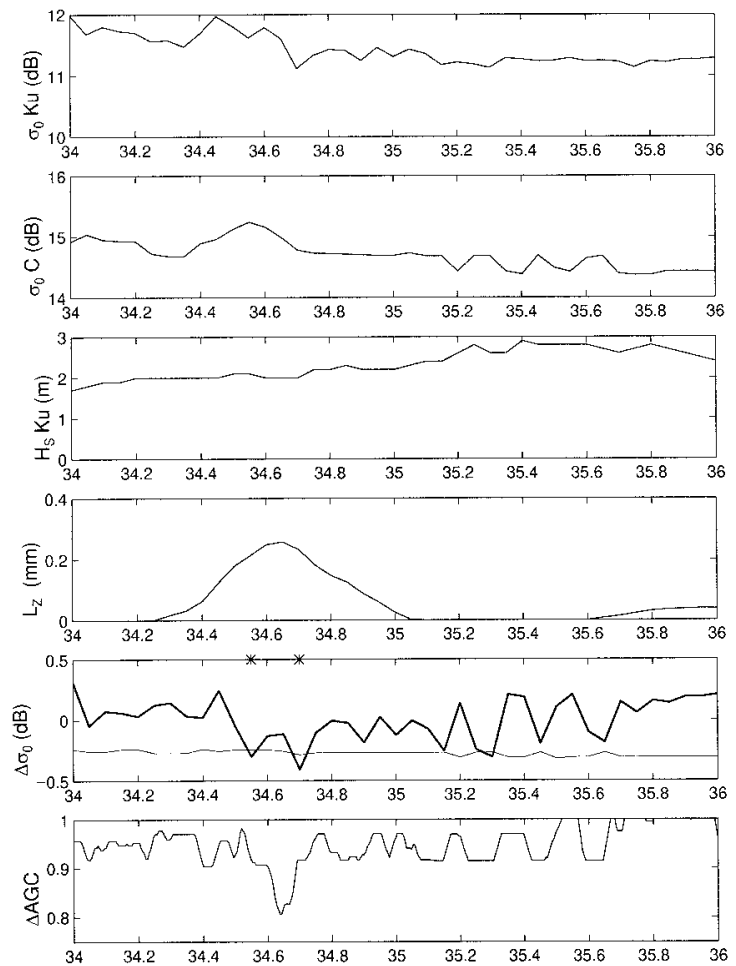

FIG. 4. TOPEX altimeter profiles for TOPEX cycle 3 pass 87 (GDR data): (a) $\sigma_{0}$ at $\mathrm{Ku}$ band, (b) $\sigma_{0}$ at $\mathrm{C}$ band, (c) significant wave height $\left(H_{S}\right)$ at $\mathrm{Ku}$ band, (c) TMR liquid water content, (d) departure from the normal C-Ku-band relationship (solid line), (e) -1.9 rms of the relation (thin line) [the stars denote the samples flagged for rain using criterion (6)], and (f) scaling factor (attenuation) of the raw waveforms estimated from the departure of normal $\mathrm{Ku}-\mathrm{C}$-band automatic gain control relationship.

NRA, $\alpha=3.14 \times 10^{-2}$ and $\beta=1.14$ (Slack et al. 1994).

Figure 2 presents the evolution of TOPEX Ku-band altimeter waveforms as the satellite passes over a rain cell for four different rain-rate and cell diameters: $R=$ $5 \mathrm{~mm} \mathrm{~h}^{-1}$ and $d=36 \mathrm{~km}$ (light rain), $R=10 \mathrm{~mm} \mathrm{~h}^{-1}$ and $d=23 \mathrm{~km}, R=20 \mathrm{~mm} \mathrm{~h}^{-1}$ and $d=13 \mathrm{~km}$, and $R=50 \mathrm{~mm} \mathrm{~h}^{-1}$ and $d=4 \mathrm{~km}$ (heavy storm). For the four cases, the rain height is fixed to $5 \mathrm{~km}$. Attenuation and distortion of the plateau (i.e., the slowly decreasing portion of the echo) are the most severe when the rain cell is centered on the satellite nadir. When the rainfall is light, attenuation is small and distortion is weak. For heavy rain, which corresponds in general to small rain cell diameters (Goldhirsh 1983), distortion is severe and can lead to tracker loss of lock and thus erroneous range and significant wave height estimates (Guymer et al. 1995).

So far, absorption, the principal effect of rain on the echo waveform, has been considered, but it is by no means the only contribution to the modification of the echo. Unexpected features in the $\sigma_{0}$ measurements by altimeter, such as enhanced backscatter in $\mathrm{Ku}$ and $\mathrm{C}$ bands, have been reported by different authors (Guymer et al. 1993; Quartly et al. 1996; Tournadre and Morland 1998). They have been associated with the modification of the sea surface roughness by rain.

Raindrops impinging on the sea surface generate ring waves spreading radially from the impact craters. The rings, which have a wavelength of $1-2 \mathrm{~cm}$ and a lifetime on the order of tens of seconds, can expand to a diameter of 25-50 cm before they disappear (Atlas 1994). They obviously increase the roughness of the surface.

At the same time, rain dampens sea waves when the surface is rough. This phenomenon has been observed for centuries, but the exact mechanism by which it occurs is not well understood. It is thought that rainfall increases the viscosity or turbulence of a thin layer near the surface and thus dampens the waves because the decay of surface gravity waves increases with viscosity. Short waves are the most severely affected, but long waves also lose their energy through wave-wave interactions. The resulting decrease in surface roughness decreases the wind stress and impedes the growth of long waves (Atlas 1994).

It is still unclear which of these two counteracting effects, roughening or smoothing of the surface, dominates for an altimeter. It is beyond the scope of the present study to analyze these effects. In the present study, we assumed that if the surface roughness is modified by rain, the change of $\sigma_{0}$ will be similar in the $\mathrm{Ku}$ and $\mathrm{C}$ bands.

\section{b. Selection of samples possibly affected by rain}

Recent studies (Morland 1994; Quartly et al. 1996, Tournadre and Morland 1998) analyzed the effects of rain on the NRA altimeter data. Using the dual frequency capability of the NRA altimeter and the fact that attenuation is almost negligible at $\mathrm{C}$ band (except for very high rain rate), they showed that departure from the normal $\mathrm{Ku}-\mathrm{C}$-band relationship can be associated with rain events. In this study we use the criteria presented by Tournadre and Morland (1998) to detect rain events. A sample is considered to be corrupted by rain if the $\sigma_{0}$ anomaly, $\Delta \sigma_{0}$, defined the deviation of the $\mathrm{Ku}-$ band $\sigma_{0}$ from its expected value given by the $\mathrm{C}$-band $\sigma_{0}$, is less than $-1.9 \mathrm{rms}$ of the observed $\mathrm{Ku}-\mathrm{C}$-band relationship $f$. As rain is expected to attenuate the $\mathrm{Ku}$ band versus the $\mathrm{C}$ band, the search is for only negative $\Delta \sigma_{0}$. To ensure that clouds are present, a second constraint is also imposed. The TOPEX microwave radiometer (TMR) liquid water content estimate $L_{z}$ (see appendix $\mathrm{B}$ ) is required to exceed $0.2 \mathrm{~mm}$ :

$$
\Delta \sigma_{0}=\sigma_{0}^{\mathrm{Ku}}-f\left(\sigma_{0}^{C}\right)<-1.9 \operatorname{rms}\left(\sigma_{0}^{C}\right)
$$

and

$$
L_{z}>0.2 \mathrm{~mm}
$$

The C-band rescaling function $f$, as well as the rms, is computed using the observed coincident $\mathrm{Ku}-$ and $\mathrm{C}$ - 

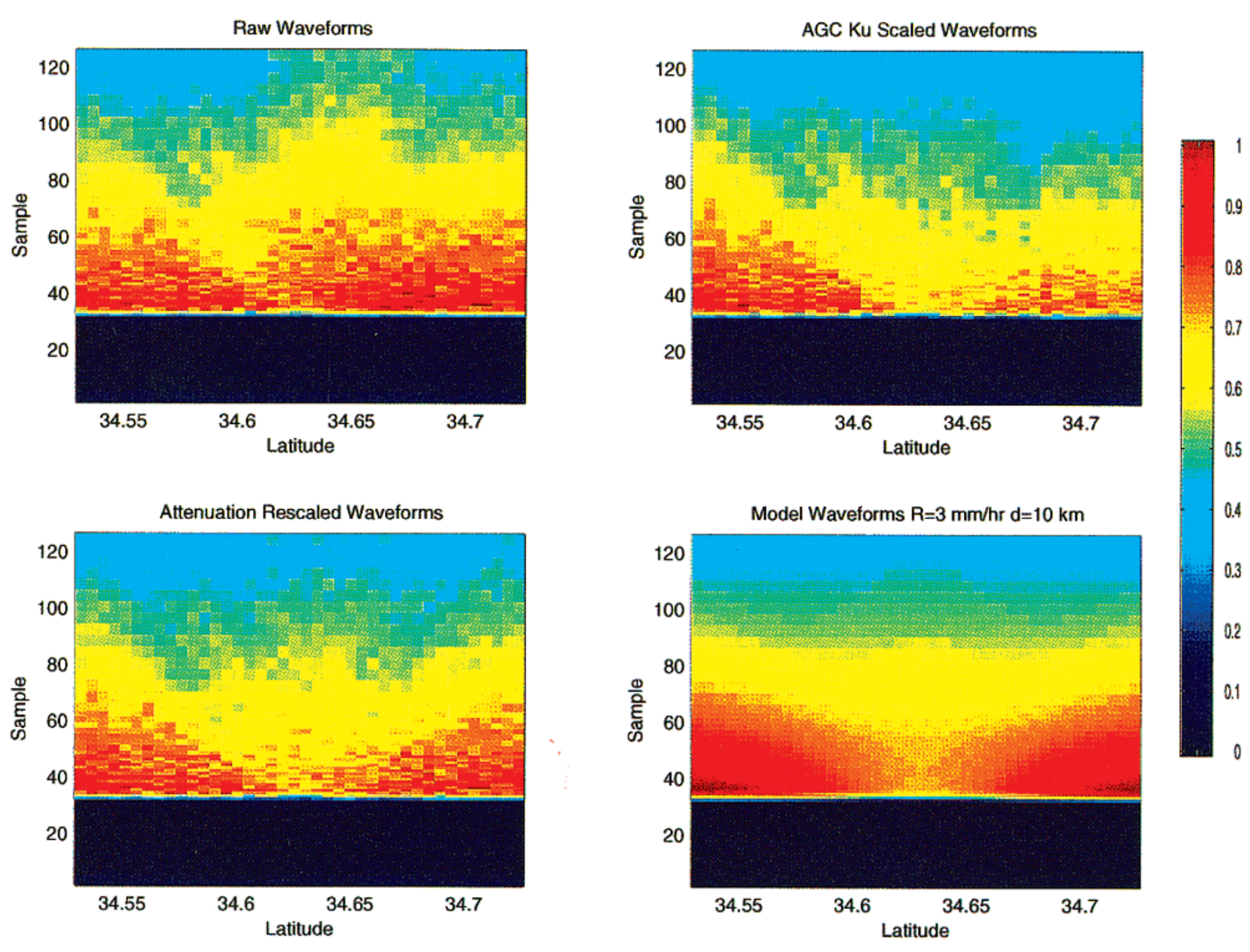

FIG. 5. TOPEX Ku-band altimeter echo corresponding to the rain cell flagged at $34.7^{\circ} \mathrm{N}$ in Fig. 4. Raw, AGC scaled, attenuation rescaled, and modeled waveforms $\left(R=3 \mathrm{~mm} \mathrm{~h}^{-1}\right.$ and $\left.d=10 \mathrm{~km}\right)$.

band $\sigma_{0}$ measurement over a whole cycle of data. This method eliminates any possible calibration problem.

\section{Determination of rain cell characteristics}

a. Method

The possible rain events are first detected in the TOPEX GDR data using relation (8). The waveforms corresponding to the detected rain events are then analyzed.

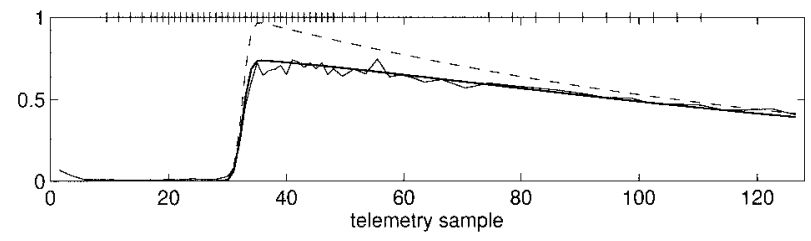

FIG. 6. Measured (thin line) and best fit of the model to the most attenuated waveform of Fig. 4. The dashed line represents an unattenuated waveform. The telemetry samples used for the minimization are represented by a plus sign.
The raw Ku-band waveforms are scaled by the departure from the normal $\mathrm{Ku}-\mathrm{C}$-band $\mathrm{AGC}$ relationship using the following relation:

$$
\sigma(t)=\sigma(t) 10^{\left[\mathrm{AGC}^{\mathrm{Ku}}-g\left(\mathrm{AGC}^{\mathrm{C}}\right)\right] / 10},
$$

where $g$ is the normal $\mathrm{Ku}-\mathrm{C}$-band AGC relation determined from the measurements over the whole cycle. This rescaling eliminates the effect of the surface (variability of the surface roughness) and only the attenuated part of the signal due to the rain is considered.

The waveform for which attenuation is maximum is assumed to correspond to the minimum distance $x_{0}$ between the satellite nadir and the rain cell center. A first estimate of the rain cell characteristics is obtained by fitting model (3) to this waveform. The fit is done by minimizing a functional $F$, defined as the mean distance in the least square sense between the measured $\sigma_{M}$ and modeled $\sigma_{m}$ waveform:

$$
F\left(R, H_{c}, d, x_{0}\right)=\frac{1}{N} \sum_{i=1}^{N}\left[\sigma_{M}\left(t_{i}\right)-\sigma_{m}\left(t_{i}\right)\right]^{2} .
$$



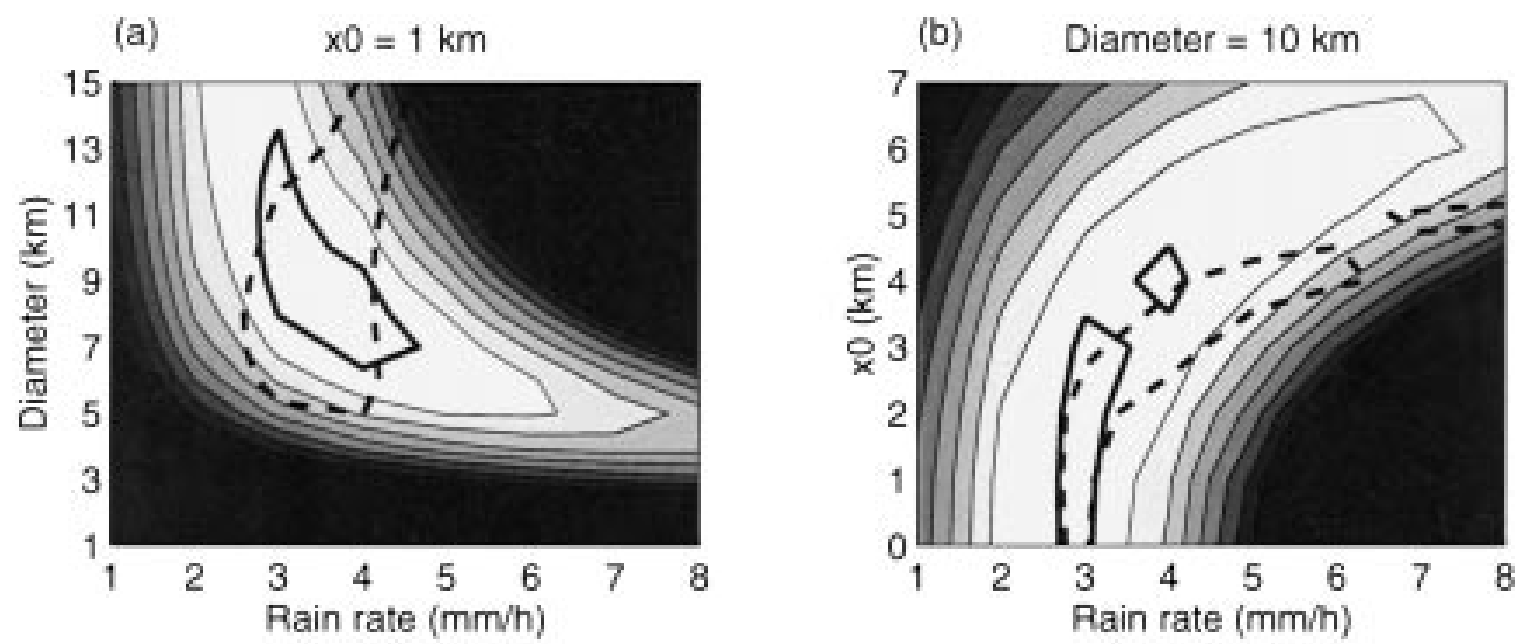

(c) Rain rate $=3 \mathrm{~mm} / \mathrm{h}$

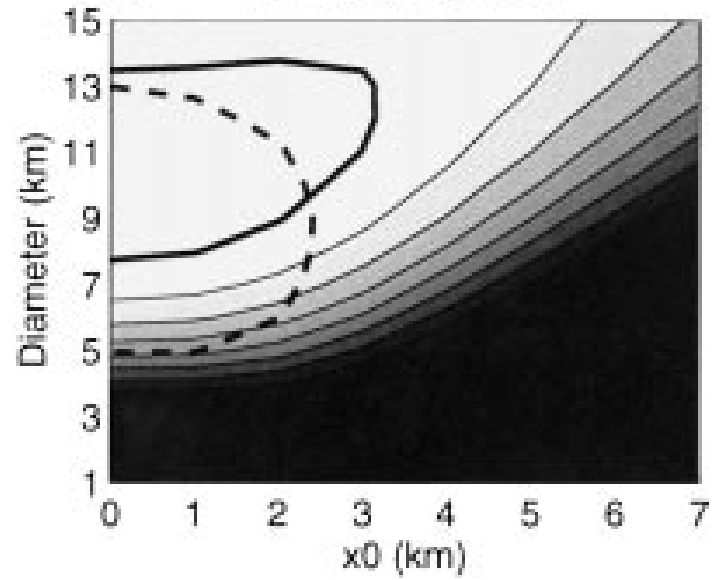

Fig. 7. Functional $F$ for the most attenuated waveform of case 1 as a function of (a) rain rate and diameter for $x_{0}=1 \mathrm{~km}$, (b) rain rate and $x_{0}$ for a diameter of $10 \mathrm{~km}$, and (c) $x_{0}$ and diameter for a rain rate of $3 \mathrm{~mm} \mathrm{~h}^{-1}$. The contours are given every $10^{-3}$. The $1 \times 10^{-3}$ isoline is represented by a thick solid line. The thick dashed line represents the 0.99 correlation line.

Only the telemetry samples $t_{i}$, where there is no problem of leakage, that is, for $i=5-44$ and 51-60, are considered (Hayne et al. 1994). The minimization algorithm is the Nelder-Meade simplex search (Nelder and Meade 1965).

As the rain cell height $H_{c}$ and the rain rate $R$ come into the model only through their product in the computation of the total attenuation $A_{R}$, the minimization is in fact conducted on this parameter. It is thus pointless to estimate $H_{c}$ and $R$ separately. For convenience, we choose to assume the rain cell height $H_{c}$ to be constant within the rain cell and fixed to $5 \mathrm{~km}$, that is, the average mean $0^{\circ} \mathrm{C}$ isotherm (Goldhirsh and Katz 1979). Based on observations of rain cells from ground-based radars in several climate regimes, Szoke et al. (1986) and Zipser and Lutz (1994) showed that the radar reflectivity (thus the rainfall) at $\mathrm{C}$ band was nearly constant between the surface and the $0^{\circ} \mathrm{C}$ isotherm (4-6 km in the Tropics) and rapidly decreased aloft. The constant height model represents a first-order representation of a rain cell and is certainly highly idealized, especially for a thunderstorm. A further development of the method could include the determination of the $0^{\circ} \mathrm{C}$ isotherm from coincident radiometer data such as the ATSR onboard the ERS satellites.

It would also be useless to seek the rain cell characteristics with high precision. The tolerance for the control parameters in the minimization procedure have thus been fixed to $0.5 \mathrm{~km}$ for $d$ and $x_{0}$ and $0.5 \mathrm{~mm} \mathrm{~h}^{-1}$ for $R$. The tolerance for the functional is fixed to $1.10^{-3}$ to take into account the noise of the waveforms.

The vector solution of the minimization is then used as a starting vector of control parameters for the minimization of the functional $F^{\prime}$ defined as the mean distance between the surface defined by the $M$ successive waveforms $\sigma_{m j}\left(t_{i}\right)$ as the satellite passes over the rain cell;

$$
F^{\prime}\left(R, d, x_{0}\right)=\frac{1}{M N} \sum_{j=1}^{M} \sum_{i=1}^{N}\left[\sigma_{M_{j}}\left(t_{i}\right)-\sigma_{m_{j}}\left(t_{i}\right)\right]^{2} .
$$



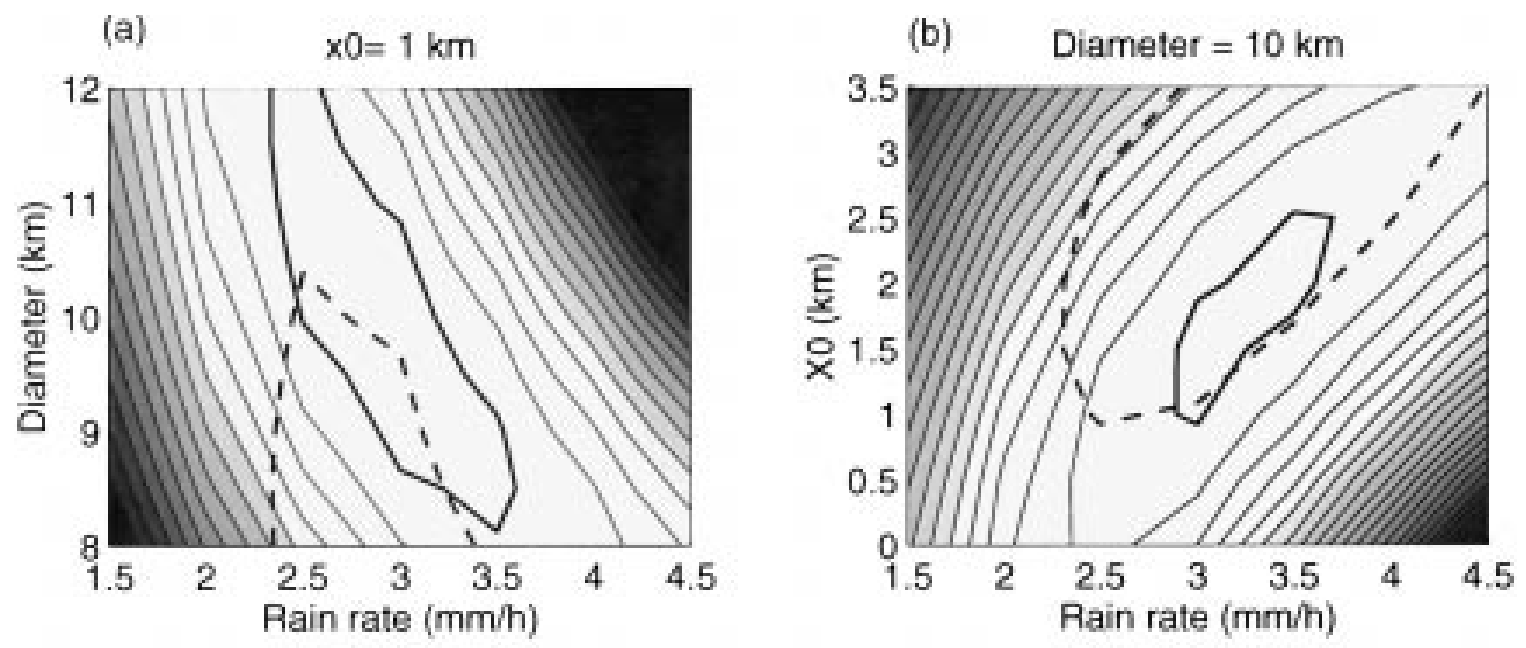

(c) Rain rate $=2.7 \mathrm{~mm} / \mathrm{h}$

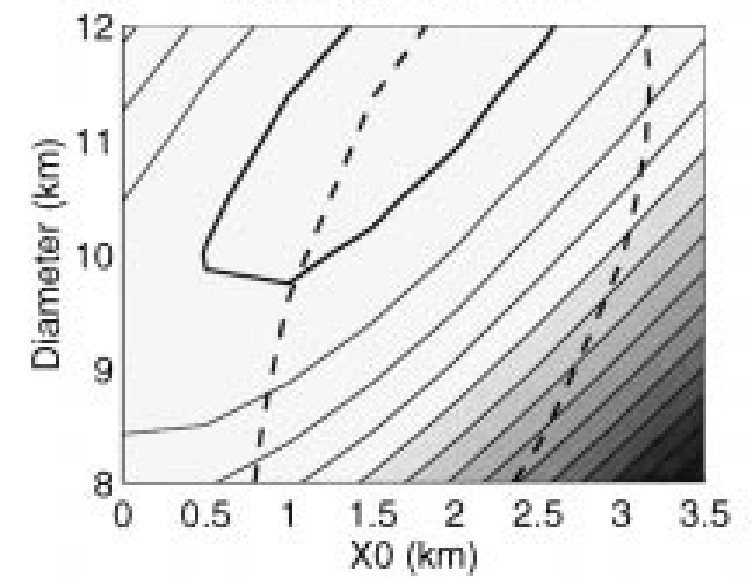

FIG. 8. Functional $F^{\prime}$ for case 1 as a function of (a) rain rate and diameter for $x_{0}=1 \mathrm{~km}$, (b) rain rate and $x_{0}$ for a diameter of $10 \mathrm{~km}$, and (c) $x_{0}$ and diameter for a rain rate of $2.7 \mathrm{~mm} \mathrm{~h}^{-1}$. The contours are given every $10^{-3}$. The $2 \times 10^{-3}$ isoline is represented by a thick solid line. The thick dashed line represents the 0.99 correlation line.

The tolerance constraints for the control parameters are the same as previously stated. Because of the noise level of the waveforms and as the surface is in general not exactly symmetrical on both sides of the most attenuated waveform, the termination tolerance for the functional has to be weaker for the surface of waveforms than for a single one. Two convergence criteria are thus applied: 1) the distance between the model and measured waveforms has to be less than $2 \times 10^{-3}$ and 2) the correlation between the two surfaces has to be larger than 0.98 to ensure that the shapes of the surfaces are similar.

As rain is highly sporadic in time and space, it is very difficult to carry out simultaneous in situ and remote-sensing measurements of rain cells. It is thus very difficult to validate the results of the method presented. It is, however, possible to estimate the accuracy of the method by testing the convergence of the minimization procedure. This will be done for several rain cells.

\section{b. Problems to overcome}

When the altimeter tracker loses lock because of strong distortion, the waveforms are shifted to smaller time (Guymer et al. 1995) (see Fig. 11). The onboard waveform fitting algorithm no longer works properly and erroneous range, attitude, and significant wave height estimates are produced. When the leading edge of the waveforms is still present in the data, it is possible to retrack the waveforms using a procedure based on the detection of the leading edge. The first sample where the signal becomes larger than the thermal noise can be considered as the beginning of the leading edge of the waveform. It can be detected using a gradient criterion. The position of the beginning of the leading edge is, as expected, remarkably stable outside rain cells and its variation is less than one sample. When a shift is detected for a particular waveform, the range shift is estimated by the difference with the normal leading edge position. The waveforms are then repositioned, taking 


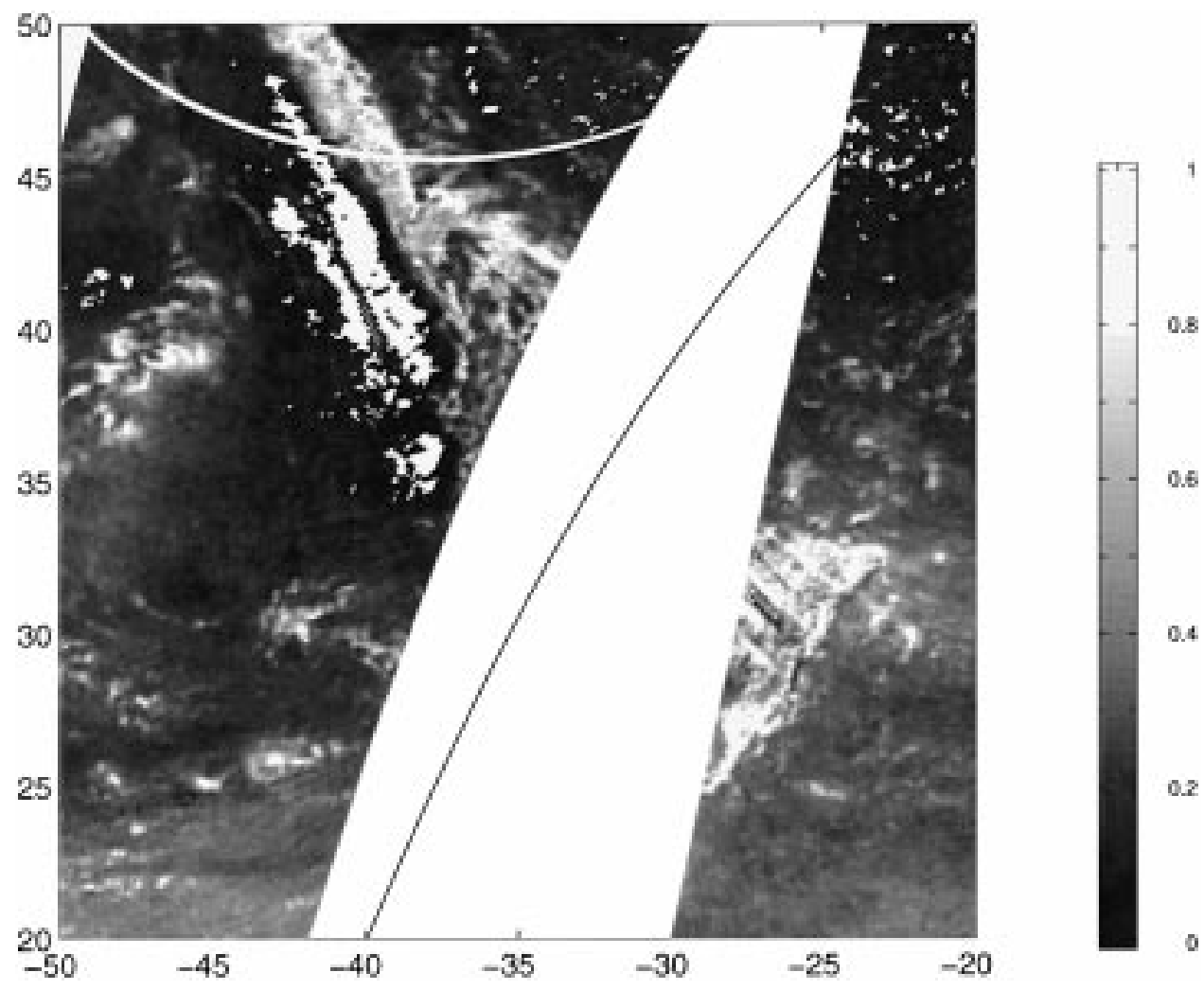

FIG. 9. SSM/I liquid water content, $\mathrm{LW}_{85}\left(\mathrm{~kg} \mathrm{~m}^{-2}\right)$, at 0642 and 0842 UTC 17 October 1992 and TOPEX ground track (black line) (cycle 3 pass 113, 0906 UTC 17 October 1992).

into account the timing of the telemetry samples as a function of onboard samples. This procedure is only designed to rematch the waveform and does not aim to conduct any range estimate.

\section{Case studies}

Several case studies corresponding to different rain cell sizes and rain rates are presented in this section to illustrate the method.

\section{a. An isolated light rain cell, cycle 3 pass 87 , 0844 UTC 16 October 1992}

The first case corresponds to a small isolated rain cell detected in the rear of a cold front. The SSM/I liquid water $\mathrm{LW}_{85}\left(\mathrm{~kg} \mathrm{~m}^{-2}\right)$ estimated from the $85-\mathrm{GHz}$ polarization ratio (Petty 1990; Petty and Katsaros 1992) at $0720 \mathrm{UTC}$, that is, $1 \mathrm{~h}$ before the TOPEX pass, presented in Fig. 3, shows the presence of small clouds near $34^{\circ} \mathrm{N}$ characterized by liquid water contents around $0.5 \mathrm{~kg} \mathrm{~m}^{-2}$. This level of liquid water is not large enough to ascertain the presence of rain. Figure 4 presents the GDR's $\mathrm{Ku}$ - and C-band $\sigma_{0}$ 's, significant wave height, and the TMR liquid water content measured around $34^{\circ} \mathrm{N}$. The Ku-band $\sigma_{0}$ is attenuated compared to the $\mathrm{C}$ band at $34.6^{\circ}$, where $L_{z}$ reaches a local maximum of
$0.25 \mathrm{~mm}$. The rain detection criterion signals two GDR samples near $34.6^{\circ} \mathrm{N}$. The waveforms corresponding to the GDR samples between $34.4^{\circ}$ and $34.8^{\circ} \mathrm{N}$ were extracted from the SDR and rescaled by attenuation.

A V-shaped pattern typical of the presence of a rain cell is visible in Fig. 5 near $34.7^{\circ} \mathrm{N}$. A rainfall rate of $2 \mathrm{~mm} \mathrm{~h}^{-1}$ was estimated from the attenuation of $\mathrm{Ku}-$ band versus C-band $\sigma_{0}(0.45 \mathrm{~dB})$, using the MarshallPalmer relation. Attenuation reaches its maximum at $34.65^{\circ} \mathrm{N}$. The model fitting of this most attenuated waveform gives the following rain cell characteristics: $R=$ $3 \mathrm{~mm} \mathrm{~h}^{-1}, d=11 \mathrm{~km}$, and $x_{0}=1 \mathrm{~km}$. The modeled and measured waveforms are given in Fig. 6. The fit of the 40 waveforms affected by the rain cell gives similar results, that is, $R=3 \mathrm{~mm} \mathrm{~h}^{-1}, d=10 \mathrm{~km}$, and $x_{0}=$ $1 \mathrm{~km}$. The correlation between the model and measured waveforms is $99.3 \%$.

This example shows that even a very light rain cell gives a signature strong enough in the altimeter waveforms to be detected and its characteristics to be retrieved. Because of their resolution of the order of tens of kilometers (17 km for SSM/I channel $85.5 \mathrm{GHz}$ and $30 \mathrm{~km}$ for TMR channel $22.2 \mathrm{GHz}$ ), passive microwave radiometers are unable to detect rain in these cases. If we consider the present rain cell, a rain rate of $3 \mathrm{~mm}$ $\mathrm{h}^{-1}$ corresponds roughly to a water content of $2 \mathrm{~g} \mathrm{~cm}^{-3}$ (Ulaby et al. 1981, 319) and thus to an integrated liquid 
water content of approximately $1 \mathrm{~mm}$ for a $5-\mathrm{km}$ height rain cell. The total liquid water content of the rain cell can be estimated by integration of (1), that is, $1.13 \times$ $10^{5} \mathrm{~m}^{3}$. By simple geometric consideration, a radiometer with a resolution of $17 \mathrm{~km}$, such as SSM/I channel 85 , will measure a mean liquid water content of $0.5 \mathrm{~mm}$ (or $\mathrm{kg} \mathrm{m}^{-2}$ ) and a radiometer with a resolution of 36 $\mathrm{km}$, such as TMR $(22 \mathrm{GHz})$, will only detect a liquid water content of $0.15 \mathrm{~mm}$. These values agree well with the ones observed by both SSM/I and TMR.

\section{b. Accuracy of the method}

A light rain cell constitutes a good case to test the precision of the determination of the rain cell characteristics because the deformation of the waveforms is weak (see Fig. 2). For this rain cell, the functionals $F$ and $F^{\prime}$ have been estimated for different values of the variables $R, d$, and $x_{0}$. The isolines of the functional in three orthogonal planes near the functional minimum are presented in Figs. 7 and 8. The thick solid line delineates the region where the convergence criterion is met and the thick dashed line the region where correlation is above $99 \%$. For the most attenuated waveform, the minimum of $F$ is well defined for constant $x_{0}$ and diameter $d$. It is less well defined for a constant rain rate mainly because, as can be seen in Eq. (3), the modeled waveform is dependent on the ratio $x_{0} / r$. The range of convergence in $R$ is [2-4] $\mathrm{mm} \mathrm{h}^{-1}$. For the rain cell diameter $d$, the convergence range is [8-13] $\mathrm{km}$, and for the distance $x_{0}$, the region of convergence is [0-3] $\mathrm{km}$. For almost all of this region, the correlation is near or above $99 \%$.

The fitting of all the attenuated waveforms allows one to reduce the uncertainties on the diameter and distance. The region of convergence of $F^{\prime}$ is $2.5 \mathrm{~mm} \mathrm{~h}^{-1}<R<$ $3.5 \mathrm{~mm} \mathrm{~h}^{-1}, 8 \mathrm{~km}<d<12 \mathrm{~km}$, and $1 \mathrm{~km}<x_{0}<$ $2.5 \mathrm{~km}$.

For low to moderate rain rates $\left(<15 \mathrm{~mm} \mathrm{~h}^{-1}\right)$, the variation of the attenuation $A_{R}$ with rain rate is strong, and it is reasonable to think that the accuracy of the method will be of the order of $1-2 \mathrm{~mm} \mathrm{~h}^{-1}$ for rain rate. For higher rain rates, $A_{R}$ asymptotically tends toward -1 and the accuracy of rain-rate estimates will certainly degrade. For rain rates above $25 \mathrm{~mm} \mathrm{~h}^{-1}$ (for which $A_{R}$ $=-0.95)$ only a gross estimate can be given.

As the estimates of the rain cell diameter and distance depend mainly on the number of affected waveforms and telemetry samples, their accuracy will be independent of the rain rate and will be of the order of $2 \mathrm{~km}$ for diameter and $1 \mathrm{~km}$ for distance.

The region of convergence of the functional $F^{\prime}$ will be given for different rain cells in the following sections.

\section{c. A large rainband of heavy rainfall, cycle 3 pass 113, 0906 UTC 17 October 1992}

The second example illustrates a more complex case where several rain cells are encountered when the sat-
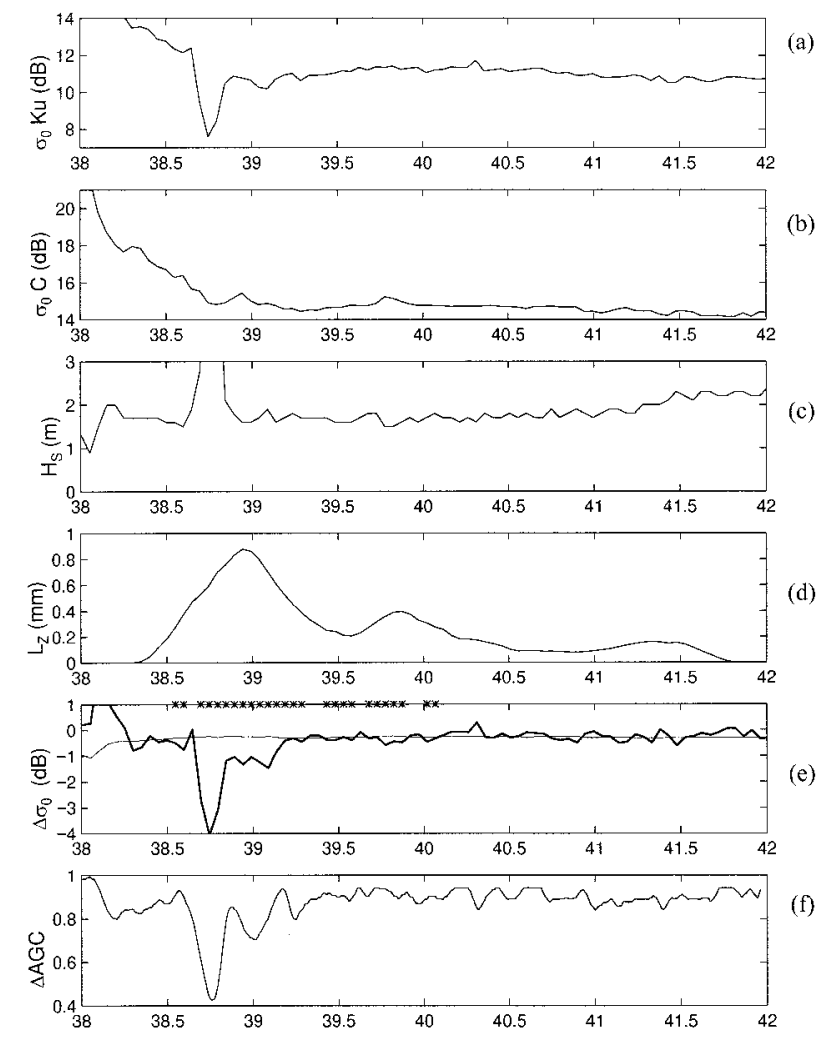

FIG. 10. Same as in Fig. 4 for TOPEX cycle 3 pass 113.

ellite passed over a North Atlantic low pressure system. Figure 9 presents the SSM/I 85-GHz rain index for two passes at 0642 and 0824 UTC and the TOPEX ground track. Near $40^{\circ} \mathrm{N}$, squall lines associated with the cyclone conveyor belt are clearly visible. Figure 10 presents the GDR data between $38^{\circ}$ and $42^{\circ} \mathrm{N}$. A large drop in $\mathrm{Ku}$-band $\sigma_{0}$ is observed between $38.5^{\circ}$ and $39^{\circ} \mathrm{N}$, which is associated with $L_{z}$ values close to the TMR rain threshold of $1 \mathrm{~mm}$. It is followed by two smaller drops between $39^{\circ}$ and $39.5^{\circ} \mathrm{N}$. Within the larger rain cell, erroneous significant wave height estimates are produced. The rain flag is triggered between $38.7^{\circ}$ and $40.35^{\circ} \mathrm{N}$.

Between $38.7^{\circ}$ and $38.9^{\circ} \mathrm{N}$, the waveforms are highly distorted (Fig. 11a), causing the tracker to lose lock. These waveforms have been retracked using the method described in section 4 and then AGC rescaled using (7). The retracked waveforms are presented in Fig. 11b. Three rain cells corresponding to the three drops of $\mathrm{Ku}-$ band $\sigma_{0}$ can be identified at $38.7^{\circ}, 39^{\circ}$, and $39.2^{\circ} \mathrm{N}$.

Table 1 summarizes the results of the analysis of the three rain cells. The Ku-band signal is attenuated by 4 $\mathrm{dB}$ for the larger rain cell. For a 5-km-thick uniform rain cell filling completely the altimeter footprint, this attenuation corresponds to a rain rate $R$ of $10 \mathrm{~mm} \mathrm{~h}^{-1}$. A similar computation gives rain rates of 3.7 and $3 \mathrm{~mm}$ $\mathrm{h}^{-1}$ for the two other cells. The best fit on the most attenuated waveform gives a rain cell of $16 \mathrm{~mm} \mathrm{~h}^{-1}, 9$ - 


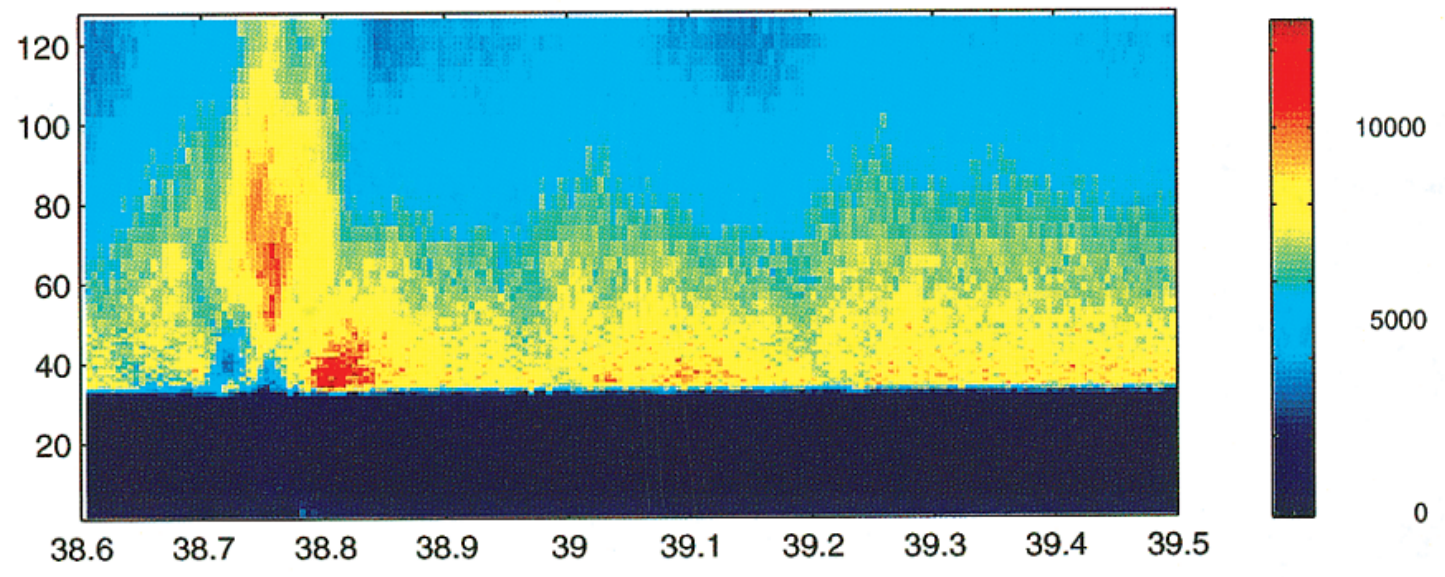

(a)

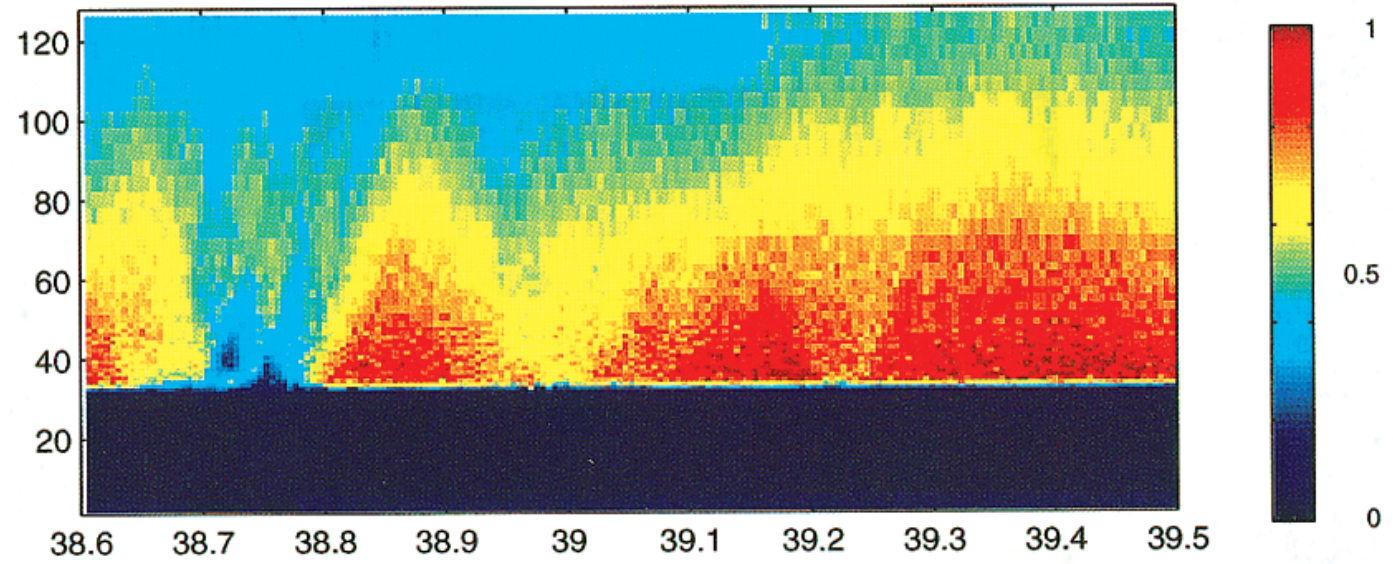

(b)

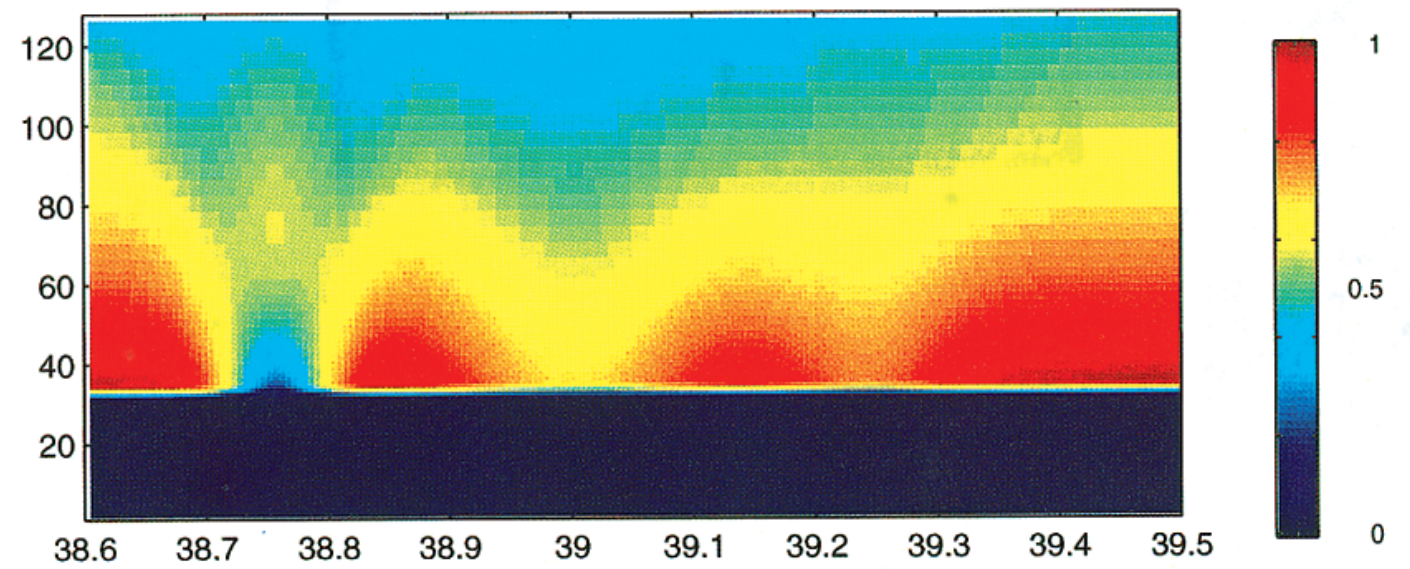

(c)

FIG. 11. (a) Raw, (b) attenuation rescaled, and (c) modeled waveforms corresponding to the three rain cells flagged in Fig. 10.

$\mathrm{km}$ diameter, and $x_{0}=0 \mathrm{~km}$; the fit of the waveforms from $38.6^{\circ}$ to $38.9^{\circ} \mathrm{N}$ (50 waveforms) gives nearly the same characteristics: $R=16 \mathrm{~mm} \mathrm{~h}^{-1}, d=10 \mathrm{~km}$, and $x_{0}=0 \mathrm{~km}$. The region of convergence of $F^{\prime}$ given in
Table 1 shows that the accuracy of the estimates is 2 $\mathrm{mm} \mathrm{h}^{-1}$ for the rain rate, $1 \mathrm{~km}$ for the diameter, and 2 $\mathrm{km}$ for the distance. The correlation reaches $98 \%$. The distribution of rain within this cell is not exactly Gauss- 
TABLE 1. Modelization of the three rain cells of the second case study. The region of convergence of the functional $F^{\prime}$ is given in brackets.

\begin{tabular}{|c|c|c|c|c|}
\hline & Cell No. & $R_{0}\left(\mathrm{~mm} \mathrm{~h}^{-1}\right)$ & $d(\mathrm{~km})$ & $X_{0}(\mathrm{~km})$ \\
\hline \multirow[t]{3}{*}{ Marshall-Palmer relation } & 1 & 10.0 & - & - \\
\hline & 2 & 3.7 & - & - \\
\hline & 3 & 3.0 & - & - \\
\hline \multirow[t]{3}{*}{ Most attenuated waveform } & 1 & 16.0 & 9 & 0 \\
\hline & 2 & 4 & 17 & 0 \\
\hline & 3 & 3 & 12 & 0 \\
\hline \multirow[t]{3}{*}{ All waveforms } & 1 & $16[14-18]$ & $10[9-11]$ & $0[0-2]$ \\
\hline & 2 & $4[3-5]$ & $22[18-22]$ & $0[0-2]$ \\
\hline & 3 & $3[2-4]$ & $14[13-15]$ & $0[0-1]$ \\
\hline
\end{tabular}

ian but presents variations that can explain the splitting of the area of maximum attenuation near $38.75^{\circ} \mathrm{N}$.

The analysis of the two others rain cells gives the following characteristics: $R=4 \mathrm{~mm} \mathrm{~h}^{-1}, d=22 \mathrm{~km}$, and $R=3 \mathrm{~mm} \mathrm{~h}^{-1}, d=14 \mathrm{~km}$. The regions of convergence of $F^{\prime}$ are comparable to the one presented for the first case study. The three rain characteristics have been used to compute the model waveforms between $38.8^{\circ}$ and $39.5^{\circ} \mathrm{N}$. The attenuation resulting from each cell has been taken into account for the waveforms where the effect of different cells overlap.

The analysis of waveforms allows the detection of three rain cells with very different characteristics where a microwave radiometer detects only a nonprecipitating cloud using the $1-\mathrm{mm}$ threshold or a $50-\mathrm{km}$-long pre- cipitating one using the newly proposed 0.6-mm threshold.

\section{d. A small intense rain cell, cycle 3 pass 11, 0930 UTC 13 October 1992}

A small rain cell was detected at $35.8^{\circ} \mathrm{N}$ in the cycle 3 pass 11 TOPEX data when the satellite overflew the conveyor belt of a North Atlantic low pressure system. The presence of convective cells is confirmed by the $\mathrm{SSM} / \mathrm{I} \mathrm{LW} \mathrm{LW}_{85}$ liquid water content (Fig. 12). A sharp four-sample long drop in Ku-band $\sigma_{0}$ is observed at $35.75^{\circ} \mathrm{N}$ (Fig. 13); attenuation reaches $3 \mathrm{~dB}$ but $L_{Z}$ barely exceeds $0.2 \mathrm{~mm}$. The 40 waveforms corresponding

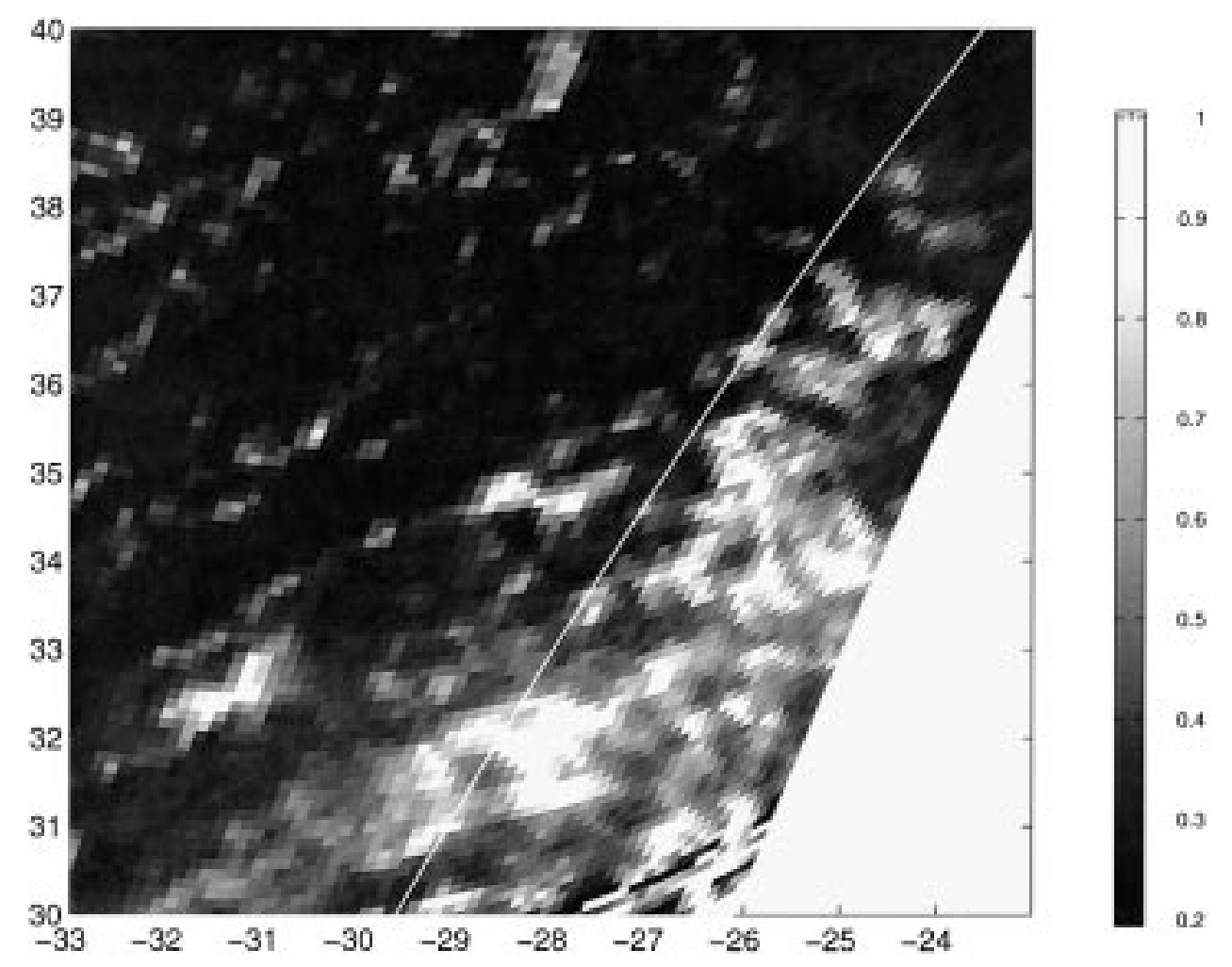

FIG. 12. SSM/I liquid water content, $\mathrm{LW}_{85}\left(\mathrm{~kg} \mathrm{~m}^{-2}\right)$, at 0734 UTC 13 October 1992 and TOPEX cycle 8 pass 202 ground track (white line) at 0930 UTC 13 October 1992. 

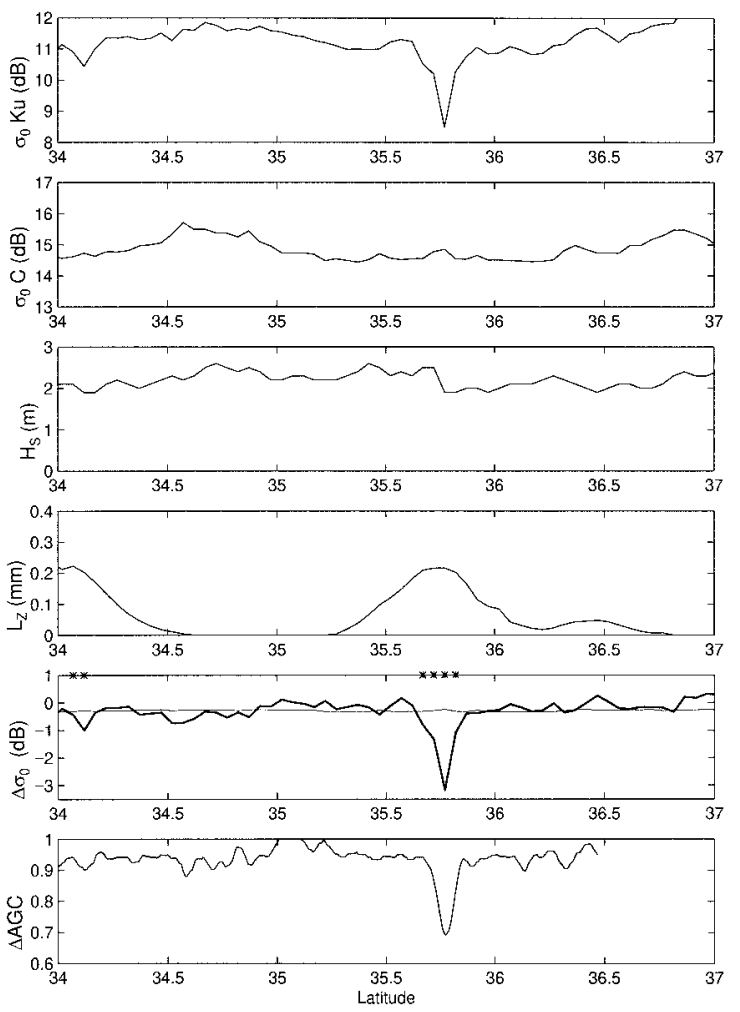

FIG. 13. Same as in Fig. 4 for TOPEX cycle 3 pass 13 (GDR data).

to the four GDR samples flagged for rain are presented in Fig. 14.

For this particular case, the simple idealized Gaussian rain cell model is not suitable, and the minimization algorithm does not converge. The two V-shaped patterns noticeable in the waveforms suggest that two adjacent rain cells might be present or that the rainfall variation within the cell is strong. For this case, the model was first fit to the waveforms with weak constraints to get a first estimate of the larger rain cell characteristics. Its contribution was then subtracted from the waveforms to estimate the contribution of the intense core. A minimization was then conducted on this contribution. The characteristics of both cells were then iteratively estimated.

As the Gaussian falloff cell model was not converging for the intense core, the constant cell model was used and shown to converge. The analysis reveals that a rain cell of $10-\mathrm{km}$ diameter and rain rate of $7 \mathrm{~mm} \mathrm{~h}^{-1}$ contained a small intense core of 4-km diameter located 5 $\mathrm{km}$ away from the satellite nadir where the rain rate exceeded $25 \mathrm{~mm} \mathrm{~h}^{-1}$.

With the weaker constraints imposed on the convergence of the functional, the regions of convergence for the two embedded rain cells are larger than for the previous examples, especially for the rain-rate estimates. For the larger rain cell the accuracy is $3 \mathrm{~mm} \mathrm{~h}^{-1}$ for rain rate, $2 \mathrm{~km}$ for diameter, and $1 \mathrm{~km}$ for distance. For the intense core, no estimate of the rain-rate uncertainty can be given as all rain rates above $25 \mathrm{~mm} \mathrm{~h}^{-1}$ that correspond to an extinction of the signal within the rain cell will give the same results. The uncertainty is $1 \mathrm{~km}$ for the diameter and $1 \mathrm{~km}$ for distance.

The model waveforms for the rain cell and for the core are presented in Fig. 14 as well as the final model. The correlation between model and measured waveforms is lower than for the previous two cases (96\%). However, the model can describe a rain event of very small extent and can give a first insight of the distribution of rain within a cell.

\section{e. Tropical Cyclone Elsie, cycle 5 pass 75 , 1723 UTC 4 November 1992}

During the first week of November 1992, the Tropical Cyclone Elsie crossed the western Pacific. On 4 November, the TOPEX/Poseidon satellite passed over the cyclone at 1723 UTC. The 85-GHz (V-polarized) SSM/I brightness temperature (K) (1947 UTC 4 November 1992), presented in Fig. 15, gives an image of the structure of the cyclone. Under such extreme conditions, the algorithm of liquid water content estimated from SSM/I brightness temperature reaches its limits, and the results are not fully validated.

The rain is so intense near the cyclone center that the altimeter loses track several times. Several $\sigma_{0} \mathrm{Ku}$-band measurements are flagged and discarded in GDR's files (Fig. 16). Values as low as $2 \mathrm{~dB}$ are measured between $15^{\circ}$ and $17^{\circ} \mathrm{N}$. Erroneous significant wave height values are also observed. The TMR liquid water content exceeds $1 \mathrm{~mm}$ between $14.5^{\circ}$ and $18.5^{\circ} \mathrm{N}$.

The values reached by $\sigma_{0}$ in both $\mathrm{Ku}$ and $\mathrm{C}$ bands are so low that the relationship between the two bands had to be interpolated for small $\sigma_{0}$ values in order to detect the rain-affected altimeter samples. The samples flagged for rain by the $\sigma_{0}$ criterion are almost identical to the ones flagged by TMR. The relation between $\mathrm{Ku}-$ and C-band AGCs has also been interpolated for small values to estimate the attenuation from the SDRs.

Attenuation and distortion are sometimes so strong that no valuable information can be retrieved, as seen in Fig. 16. The corresponding waveforms are discarded prior to the analysis. The tracker loses lock after almost every rain cell and several waveforms are shifted. The retracked and rescaled waveforms used for the analysis are presented in Fig. 17.

One of the main difficulties of the analysis comes from the overlapping of the different rain cells. To overcome this problem, the minimization algorithm is first applied to the southernmost cell. The contribution from this rain cell is then subtracted from the waveforms, and the characteristics of the second rain cell are estimated and so on until the last rain cell is analyzed.

A second problem results from the saturation of attenuation at $\mathrm{Ku}$ band for rain rates greater than $25 \mathrm{~mm}$ $\mathrm{h}^{-1}$. For such high rain rates, the signal at $\mathrm{Ku}$ band is 
(a)

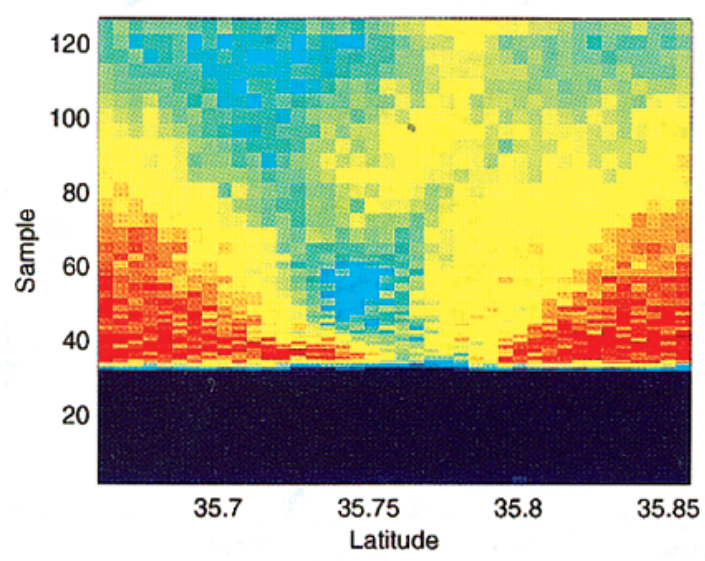

(c)

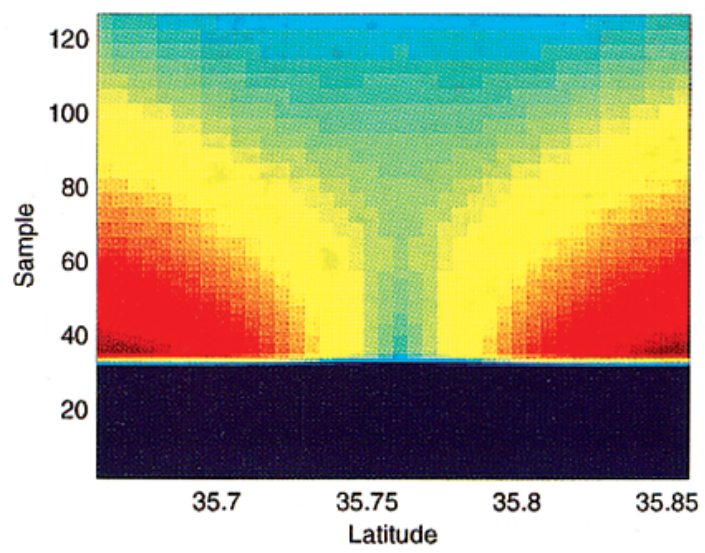

(b)

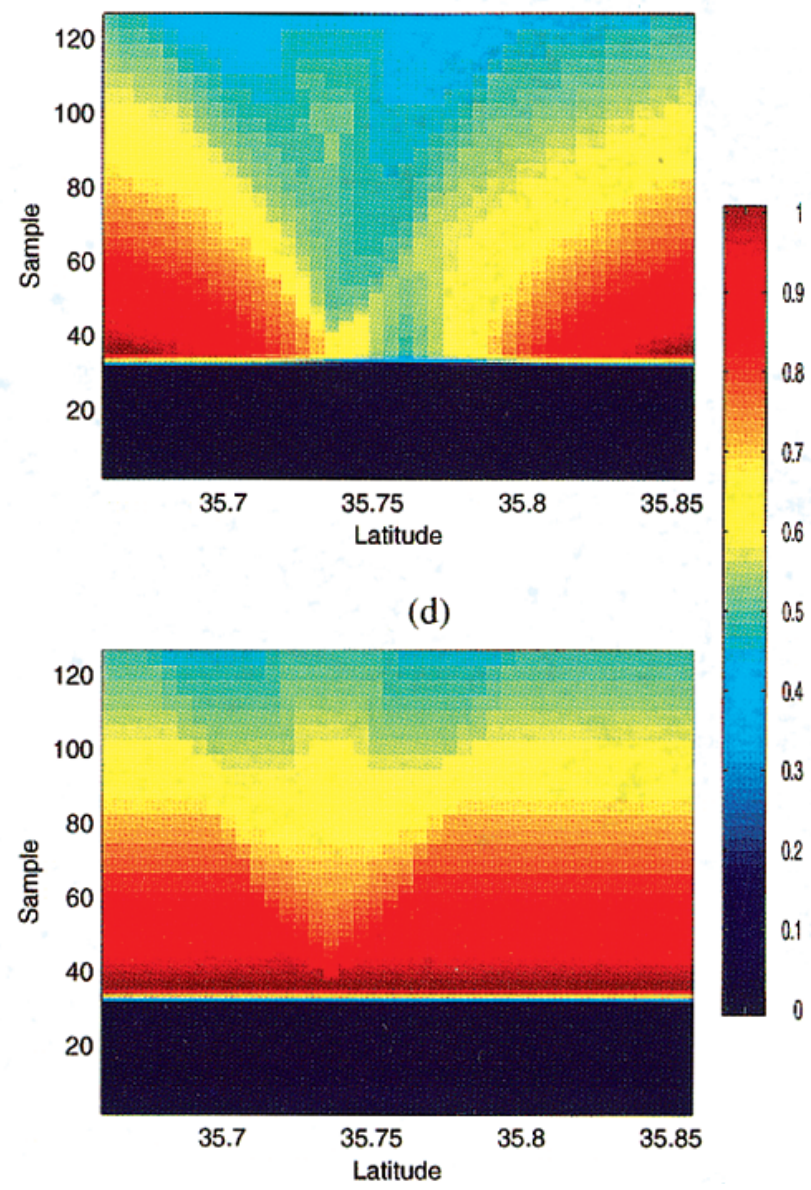

FIG. 14. (a) Attenuation rescaled waveforms corresponding to the rain cell at $35.75^{\circ} \mathrm{N}$ in Fig. 13 , (b) model waveforms including (c) a light rain cell $\left(R=7 \mathrm{~mm} \mathrm{~h}^{-1}, d=10 \mathrm{~km}\right)$, and $(\mathrm{d})$ an intense rainfall core $\left(R=25 \mathrm{~mm} \mathrm{~h}^{-1}, d=4 \mathrm{~km}, x_{0}=5 \mathrm{~km}\right)$.

almost extinct, for example; a 5-km-thick rain cell of $25 \mathrm{~mm} \mathrm{~h}^{-1}$ attenuates the signal by more than $12 \mathrm{~dB}$. This occurs, for example, between $15.5^{\circ}$ and $16^{\circ} \mathrm{N}$. However, for rain rates above $25 \mathrm{~mm} \mathrm{~h}^{-1}$, attenuation at $\mathrm{C}$ band is not negligible. For the same rain cell, the two-way attenuation is $1 \mathrm{~dB}$, using the Marshall-Palmer relation (7) with $\alpha=1.79 \times 10^{-2}$ and $\beta=1.238$ (Olsen et al. 1978). Attenuation at $C$ band can be estimated from the depth of the drop observable in GDR's data. A first-order approximation of the maximum rain rate can thus be made by inverting (7).

The analysis detected 16 rain cells between $14^{\circ}$ and $18.5^{\circ} \mathrm{N}$ whose characteristics are given in Table 2 . For rain cell numbers 8 and 15, which correspond to two attenuation maxima and for which several waveforms are not usable, the fit of the model has been made for the available waveforms. As the discarded waveforms are the most attenuated ones, the rain rate might be underestimated. The rain rates estimated from the attenuation at $\mathrm{C}$-band $\sigma_{0}$ for these two cells are also given in Table 2.
Rain rates range from 4 to $35 \mathrm{~mm} \mathrm{~h}^{-1}$ and the diameters from 10 to $25 \mathrm{~km}$. Figure 18 presents the rain rate computed from the characteristics of the rain cells along the satellite track.

The general distribution of rainfall is in agreement with radar observations (Djuric 1994). The succession of convective rainbands is clearly depicted. As in the SSM/I image, the bands are clearly asymmetric, and the largest band is located on the equatorial side of the cyclone. The strongest rainfall occurs near the cyclone center and corresponds certainly to the innermost band or eyewall. This rainfall maximum is associated with very low C-band $\sigma_{0}$, without taking into account the attenuation by rain, and thus with a very high wind that certainly exceeds $30 \mathrm{~m} \mathrm{~s}^{-1}$. The analysis of waveforms also allows the detection of the space between rainbands, sometimes rain free, called moats.

\section{Conclusions and perspectives}

This study presents a first attempt to estimate rain cell characteristics, that is, diameter and rainfall rate 


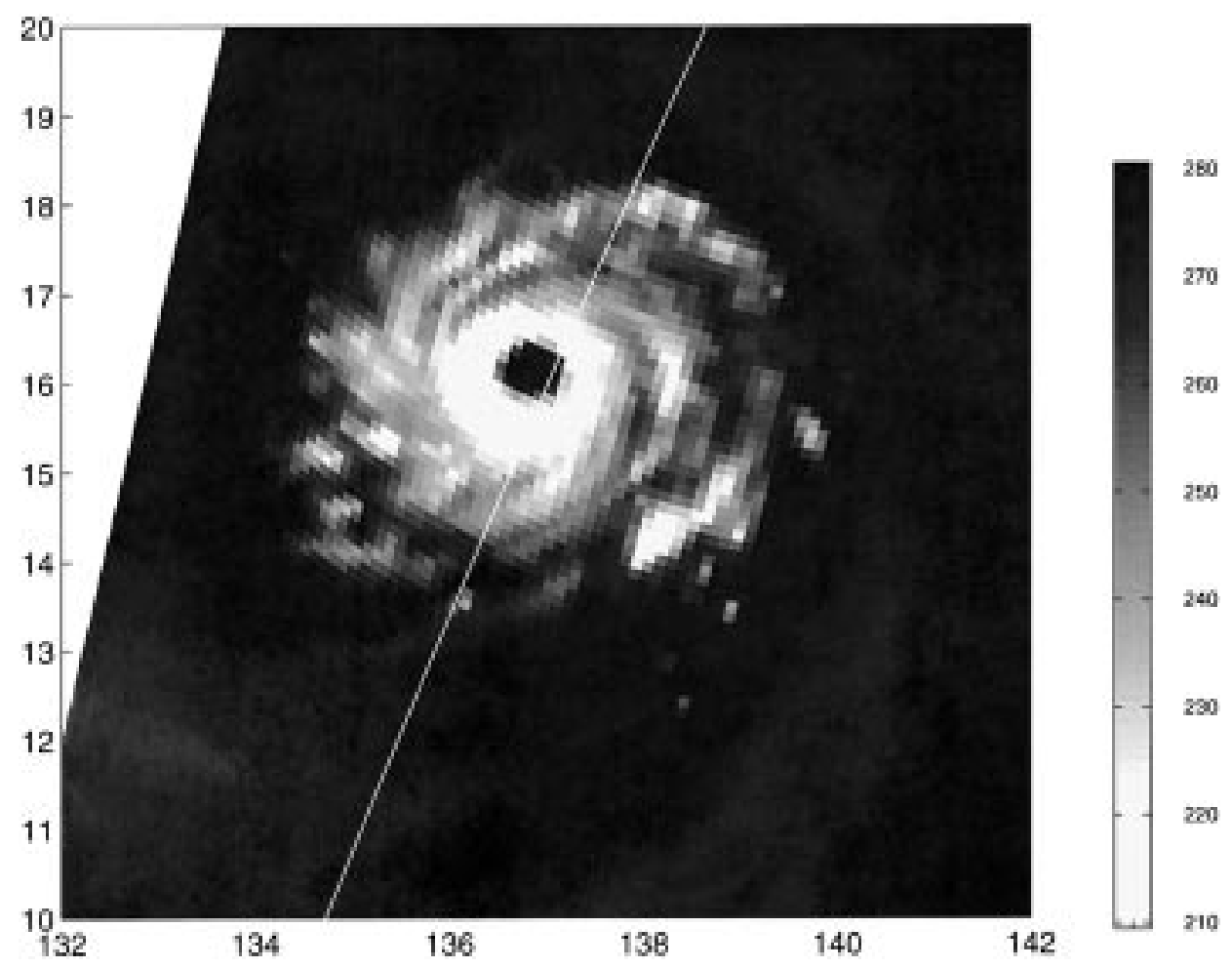

FIG. 15. SSM/I 85.5-GHz V brightness temperature at 1947 UTC 4 November 1992 over Tropical Cyclone Elsie and TOPEX ground track at 1723 UTC 4 November 1992 (cycle 5 pass 75) (white line).
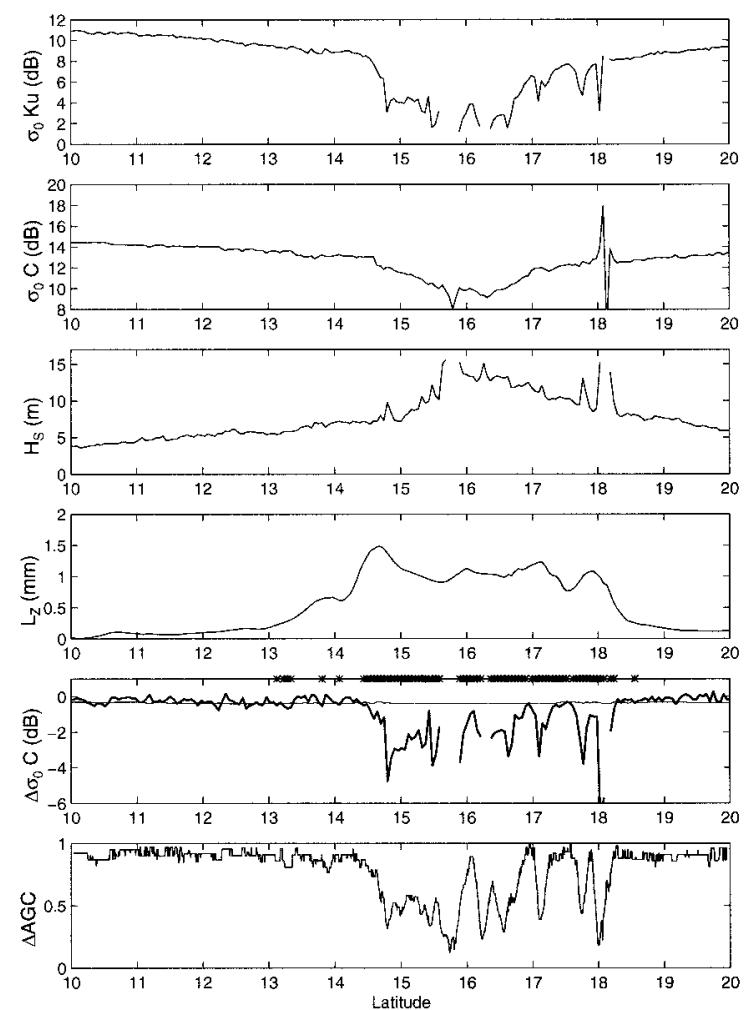

FIG. 16. Same as in Fig. 4 for TOPEX cycle 5 pass 75 (GDR data). from TOPEX/Poseidon dual frequency radar altimeter echo waveforms. The analytical formulation of altimeter echo waveform during rain events developed by Barrick and Lipa (1985) is used to model the effect of a rain cell on altimeter data. Some developments have been included to model rain-rate falloffs other than the Gaussian-like pattern used by these authors. As rain is a sporadic phenomenon and affects approximately 1\%-4\% of the altimeter samples (Petty 1995), the detection of the waveforms affected by rain is the first step to be taken in the analysis. Following the results of previous studies (Quartly et al. 1996; Tournadre and Morland 1998), the dual frequency capability of the TOPEX altimeter is used to select the waveforms possibly affected by rain. The criterion, presented by these authors and (d) used in this study, is based on a departure from a normal $\mathrm{Ku}-\mathrm{C}$-band $\sigma_{0}$ relationship and on a threshold of liquid water content measured by the TOPEX microwave radiometer. The selected waveforms are then analyzed in terms of rain cell characteristics by fitting the theoretical model.

Four case studies, corresponding to different weather conditions, have been presented to illustrate the method. (f) The method gives good results from very light rain cells to heavy rainbands associated with tropical cyclones. It allows the description of rainfall with a resolution better than a kilometer and with an accuracy of the order of 1-2 $\mathrm{mm} \mathrm{h}^{-1}$ for the rain rate, $2 \mathrm{~km}$ for the rain cell 

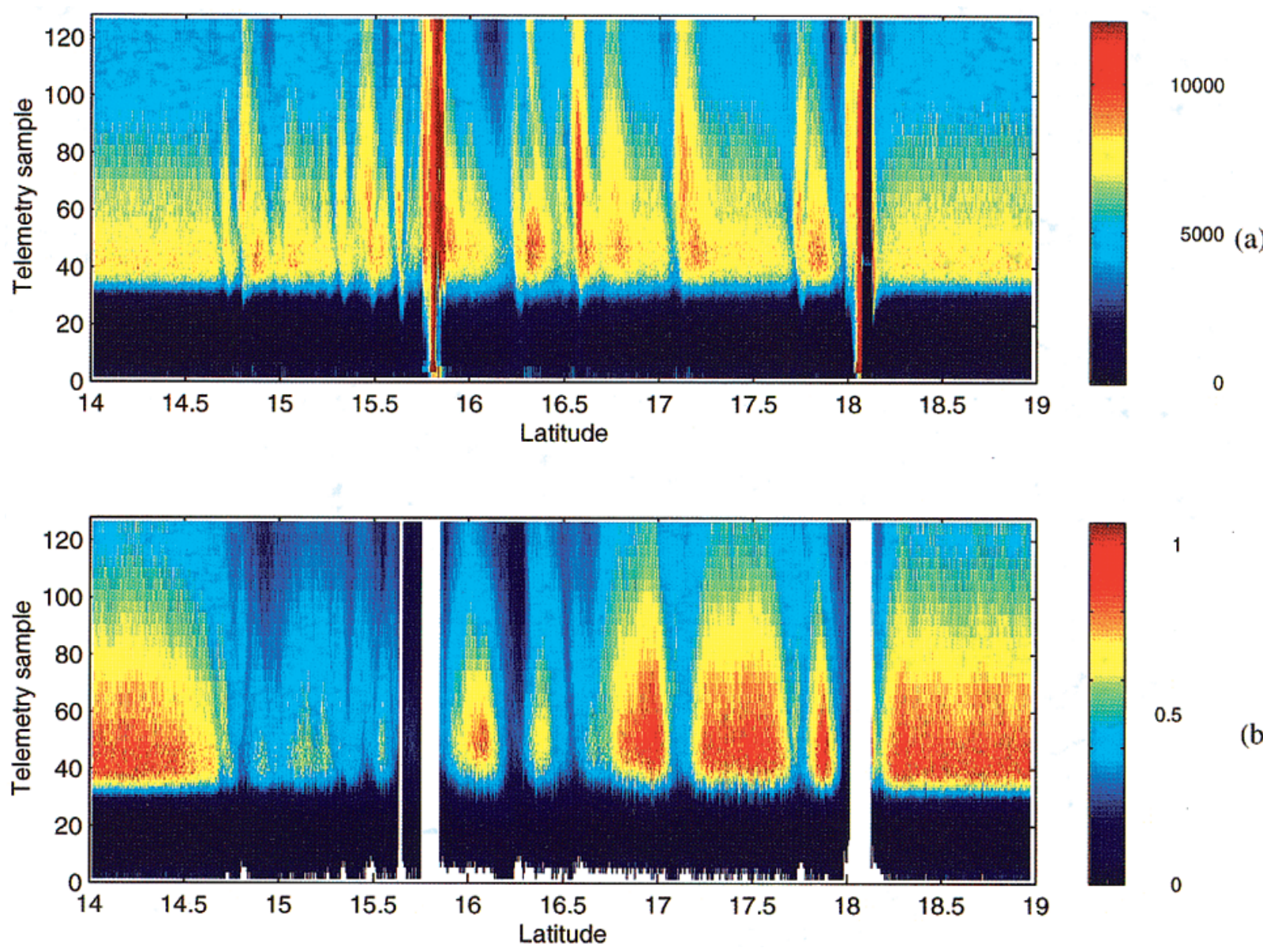

(b)

FIG. 17. (a) Raw and (b) retracked and attenuation rescaled TOPEX waveforms over Cyclone Elsie.

diameter, and $1 \mathrm{~km}$ for the distance from nadir. It could be used in conjunction with other spaceborne sensors, such as a microwave radiometer to conduct climatological studies.
In practice, the method could be used systematically in the processing facilities. During the routine processing, the data possibly affected by rain could be flagged and the corresponding waveforms selected and archived. The

TABLE 2. Rain cells characteristics for Tropical Cyclone Elsie; the "†" symbol signals the rain cells for which the maximum rain rate has been estimated using C-band attenuation, as given in parentheses.

\begin{tabular}{|c|c|c|c|c|c|}
\hline Cell No. & Latitude & $R_{0}\left(\mathrm{~mm} \mathrm{~h}^{-1}\right)$ & $d(\mathrm{~km})$ & $x_{0}(\mathrm{~km})$ & $\Delta \sigma_{0}(\mathrm{~dB})$ \\
\hline 1 & 14.63 & 10 & 10 & 5 & -1.40 \\
\hline 2 & 14.84 & 10 & 17 & 0 & -4.40 \\
\hline 3 & 14.94 & 8 & 12 & 4 & -2.80 \\
\hline 4 & 15.01 & 10 & 12 & 3 & -3.20 \\
\hline 5 & 15.20 & 6 & 20 & 5 & -2.60 \\
\hline 6 & 15.44 & 9.5 & 17 & 0 & -4.45 \\
\hline 7 & 15.51 & 5 & 10 & 5 & -3.45 \\
\hline $8 \dagger$ & 15.81 & $24(35)$ & 25 & 0 & -7.00 \\
\hline 9 & 15.88 & 9 & 10 & 0 & -4.32 \\
\hline 10 & 16.24 & 16.5 & 25 & 5 & -6.30 \\
\hline 11 & 16.54 & 11 & 12 & 0 & -4.62 \\
\hline 12 & 16.70 & 4 & 25 & 0 & -2.52 \\
\hline 13 & 17.10 & 11 & 12 & 0 & -4.10 \\
\hline 14 & 17.75 & 8.5 & 13 & 0 & -3.50 \\
\hline $15 \dagger$ & 17.94 & $25(25)$ & 20 & 0 & -5.81 \\
\hline 16 & 18.16 & 4 & 15 & 5 & -2.13 \\
\hline
\end{tabular}




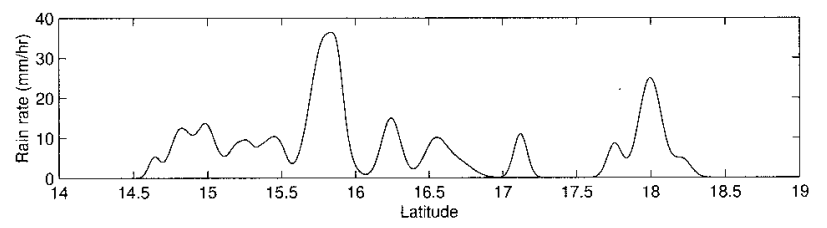

FIG. 18. Rainfall rate estimate along the TOPEX track over Cyclone Elsie.

method cannot be fully automated, and an operator would be required to process the archive either online or offline to create a global rain cell characteristics dataset. This archive could also be made accessible for scientific studies (e.g., tropical cyclones, squall lines, etc.).

The method could also be refined to include the determination of the cloud-top height from coincident radiometer data. A further development could be the determination of rainfall variation within rain cells. The rain-free echo can be subtracted from the waveforms to estimate the rain contribution and thus the attenuation for each range bin. The rain rate could then be retrieved by inversion of the waveforms.

To fully validate the method, it would also be interesting to compare the results with observations from weather radars. However, because of the sporadic nature of rain, the selection of coincident altimeter and weather radar measurements would certainly prove difficult.

Acknowledgments. The authors wish to thank B. Chapron and A. Cavanié of IFREMER for fruitful discussions and comments, and D. Vandemark and G. Hayne of the NASA/Goddard Space Flight Center for providing us copies of the SDRs and for their assistance for the waveform processing. The authors are grateful to the AVISO group for the TOPEX/Poseidon CDROMs.

\section{APPENDIX A}

\section{Model of Altimeter Echo}

The model of altimeter echo during rain events presented here is based on the work of Barrick and Lipa (1985). The radar cross section for backscatter as a function of time for an altimeter pulse and for a Gaussian random distribution of rough-surface specular points can be expressed as (Barrick 1972)

$$
\begin{aligned}
\sigma(t)= & 2 \pi^{2} a^{2}|R(0)|^{2} \\
& \times \int_{0}^{\infty} g(\psi)(\sec \theta)^{4} \sin \phi \\
& \times\left[\int_{-\infty}^{\infty} P(\xi-\zeta) p_{j}(\xi) d \xi\right] d \phi,
\end{aligned}
$$

where $\zeta$ is the sea surface elevation above the mean local surface, $\psi$ is the angle at the antenna from nadir to a point $\zeta$ of the surface, $\phi$ is the angle at the earth center from the satellite to $\zeta, g(\psi)$ is the two-way antenna normalized gain pattern, $P(x)$ is the normalized effective pulse shape as a function of spatial propagation distance $x=(c t) / 2, a$ is the earth's radius, $R(0)$ is the Fresnel reflection coefficient of the sea surface at normal incidence, $\theta$ is the angle between the local normal to the surface at $\zeta$ and the satellite, and $p_{i}(\zeta)$ is the joint height-slope distribution probability density function at elevation $\zeta$ and wave slopes corresponding to specular angle $\theta$.

Using the small-angle trigonometric approximations (as $\psi$ and $\phi$ are small), and the fact that $\zeta$ is small compared to $a$ and $H$ (satellite height), the normalized radar cross section can be expressed as

$$
\begin{aligned}
\sigma_{s}(t) & \\
= & \frac{\sigma(t)}{2 \pi^{2} H^{\prime \prime}|R(0)|^{2}} \\
& =\int_{0}^{\infty} G(u)\left[\int_{-\infty}^{\infty} P(\xi+x-u) p_{j}(\xi) d \xi\right] d u,
\end{aligned}
$$

where $\zeta=u-x$ and $u=\left(a^{2} \phi^{2}\right) /\left(2 H^{\prime \prime}\right)=\left(H^{\prime} \psi^{2}\right) / 2$, $H^{\prime}=H(1+H / a)$ is the extended satellite height, and $H^{\prime \prime}=H /(1+H / a)$ is the reduced satellite height. The new antenna gain factor is defined as $G(u)=g \sqrt{(2 u /}$ $\left.\overline{H^{\prime}}\right)$.

We assume the Gaussian shape of half-power width $\tau$ for the compressed altimeter pulse, that is, $P(x)=$ $e^{-x^{2} / 2 \sigma_{\tau}^{2}}$, with $\sigma_{\tau}=c \tau / 2 \sqrt{8 \ln 2}$. We also assume a Gaussian shape for the antenna beam pattern near its boresight. From the two-way, half-power antenna beamwidth $\psi_{H}$, we define $\psi_{b}=\psi_{H} /(8 \sqrt{\ln 2})$. Thus,

$$
g(\psi)=e^{-\left(\psi^{2} / 2 \psi_{b}^{2}\right)},
$$

and

$$
G(u)=e^{-\left(u / u_{b}\right)},
$$

where $u_{b}=\left(H^{\prime} \psi_{b}^{2}\right) / 2$.

We also assume $p_{j}$ to be Gaussian:

$$
\begin{aligned}
p_{j}(\xi) & =p(\xi, 0,0) \\
& =\frac{1}{(2 \pi)^{3 / 2} h s_{x} s_{y} \sqrt{1-\rho_{x y}^{2}}} e^{-\left(\xi^{2} / 2 h^{2}\right)},
\end{aligned}
$$

where $h$ is the rms wave height, $s_{x}$ and $s_{y}$ are the rms wave slopes along two orthogonal directions of a plane tangent to the mean sphere, and $\rho_{x y}$ is the correlation coefficient of the wave slopes along these two axes.

Under these assumptions, the cross section is given by $\sigma_{s}(t)$

$$
\begin{aligned}
& =\sigma_{s}\left(\frac{2 x}{c}\right) \\
& =\frac{\sigma_{0}}{\sqrt{2 \pi} \pi h} \int_{0}^{\infty} e^{-\left(u / u_{b}\right)}\left[\int_{-\infty}^{\infty} e^{-\left(\xi^{2} / 2 h^{2}\right)} e^{-\left[(\xi+x-u)^{2} / 2 \sigma_{\tau}^{2}\right]} d \xi\right] d u,
\end{aligned}
$$


where $\sigma_{0}=1 /\left(2 s_{x} s_{y} \sqrt{1-\rho_{x y}^{2}}\right)$ is the average normalized backscattering cross section per unit area at normal incidence.

By integration over $\xi$, (A6) can be expressed as

$$
\begin{aligned}
\sigma_{s}(t) & =\sigma_{s}\left(\frac{2 x}{c}\right) \\
& =\frac{\sigma_{\tau} \sigma_{0}}{\pi \sigma_{p}} \int_{0}^{\infty} e^{-\left(u / u_{b}\right)} e^{-\left[(x-u)^{2} / 2 \sigma_{p}^{2}\right]} d u \\
& =\frac{1}{\sqrt{2 \pi}} \sigma_{0} \sigma_{\tau}\left(1+\operatorname{erf}\left(\frac{x}{\sqrt{2} \sigma_{p}^{2}}\right)\right) e^{-\left(u / u_{b}\right)},
\end{aligned}
$$

where $\sigma s_{p}^{2}=h^{2}+\sigma s_{\tau}^{2}$.

Let us now consider a circular rain cell of height $H_{c}$, half-power diameter $d$, and displacement $x_{0}$ from the satellite nadir (Fig. 1). The rain density is assumed to fall off in a Gaussian manner from the rain cell center. The cross section can be expressed as

$\sigma_{s}(t)=\frac{\sigma_{\tau} \sigma_{0}}{\pi \sigma_{p}} \int_{0}^{\infty} e^{-\left(u / u_{b}\right)} e^{-\left[(x-u)^{2} / 2 \sigma_{p}^{2}\right]}(1+A(u)) d u$,

where $A(u)$ is the total attenuation for range $u$. Within the rain cell, the rain rate is given by

$$
R=R_{0} e^{-\left[\left(x-x_{0}\right)^{2}+y^{2}\right] / r^{2}},
$$

where $x_{0}$ is the rain cell center coordinates and $r=d l$ $(2 \sqrt{\ln 2})$. Using the small-angle trigonometric approximations, $R$ becomes

$$
R=R_{0} e^{-\left(H^{2} \psi^{2}-2 H \psi x_{0} \cos \gamma+x_{0}^{2} / r^{2}\right)},
$$

where $\gamma$ is the azimuthal angle. The two-way attenuation by rain is given by

$$
A_{R}=10^{-2 H_{c} k_{p} / 10}-1,
$$

where $k_{p}$ is the one-way signal attenuation $\left(\mathrm{dB} \mathrm{km}^{-1}\right)$ related to the rain rate by the Marshall-Palmer relationship:

$$
k_{p}=\alpha R^{\beta} .
$$

Neglecting the variation of attenuation due to the nonlinearity of the Marshall-Palmer relation, the attenuation is obtained by integration over $\gamma$;
$A(\psi)=A_{R} e^{-\left(H^{2} \psi^{2} / r^{2}\right)} e^{-\left(x_{0}^{2} / r^{2}\right)} \int_{0}^{2 \pi} e^{-\left(2 H \psi x_{0} / r^{2}\right) \cos \gamma} d \gamma$

$$
=A_{R} e^{-\left(H^{2} \psi^{2} / r^{2}\right)} e^{-\left(x_{0}^{2} / r^{2}\right)} I_{o}\left(\frac{2 H \psi x_{0}}{r^{2}}\right),
$$

where $I_{0}$ is the zero-order modified Bessel function of the first kind. Using the relationship between $u$ and $\psi$, we obtain

$$
A(u)=A_{R} e^{-\left(x_{0}^{2} / r^{2}\right)} e^{-\left(2 u H^{2} / H^{\prime} r^{2}\right)} I_{o}\left(\frac{2 x_{0} H \psi_{b}}{r^{2}} \sqrt{\frac{u}{u_{b}}}\right) .
$$

Thus, the radar cross section can be expressed as

$$
\begin{aligned}
\sigma_{N}\left(\frac{2 x}{c}\right) & \\
= & \frac{\sigma_{0} \sigma_{\tau}}{\sqrt{2 \pi}}\left[1+\operatorname{erf}\left(\frac{x}{\sqrt{2} \sigma_{p}}\right)\right] e^{-\left(x / u_{b}\right)}+\frac{\sigma_{0} \sigma_{\tau}}{\pi \sigma_{p}} A_{R} e^{-\left(x_{0}^{2} / r^{2}\right)} \\
& \times \int_{0}^{\infty} e^{-\left[(x-u)^{2} / 2 \sigma_{p}^{2}\right]-\left(u / u_{b}^{\prime}\right)} I_{o}\left(\frac{2 x_{0} H \psi_{b}}{r^{2}} \sqrt{\frac{u}{u_{b}}}\right) d u,
\end{aligned}
$$

where $u_{b}^{\prime}$ is defined by

$$
u_{b}^{\prime}=\frac{u_{b}(1+H / a)}{1+\left(2 u_{b} H\right) / r^{2}} .
$$

For a rain cell of diameter $d$ and constant rain rate $R$, by simple geometric consideration we obtain

$$
\begin{aligned}
& \sigma_{N}\left(\frac{2 x}{c}\right)= \frac{\sigma_{0} \sigma_{\tau}}{\sqrt{2 \pi}}\left[1+\operatorname{erf}\left(\frac{x}{\sqrt{2} \sigma_{p}}\right)\right] e^{-\left(x / u_{b}\right)}+\frac{\sigma_{0} \sigma_{\tau}}{\pi \sigma_{p}} A_{R} \\
&\left.\times \int_{0}^{\infty} e^{-\left[(x-u)^{2} / 2 \sigma_{p}^{2}\right]-\left(u / u^{\prime}\right)}\right) \\
& \\
& \quad \times \operatorname{acos}\left(\frac{x_{0}^{2}+\left(H^{2} u\right) / H^{\prime}-d^{2}}{2 x_{0} H \sqrt{(2 u) / H^{\prime}}}\right) d u .
\end{aligned}
$$

For a rainband of constant rain rate $R$, of width $l$, centered on $x_{0}$, by simple geometric consideration we obtain:

$$
\begin{aligned}
\sigma_{N}\left(\frac{2 x}{c}\right)= & \frac{\sigma_{0} \sigma_{\tau}}{\sqrt{2 \pi}}\left[1+\operatorname{erf}\left(\frac{x}{\sqrt{2} \sigma_{p}}\right)\right] e^{-\left(x / u_{b}\right)} \\
& +\frac{\sigma_{0} \sigma_{\tau}}{\pi \sigma_{p}} A_{R} \int_{0}^{\infty} e^{-\left[(x-u)^{2} / 2 \sigma_{p}^{2}\right]-\left(u / u_{u}^{\prime}\right)}\left(\arccos \left(\frac{H^{\prime}\left(x_{0}-l\right)}{2 u H}\right)-\arccos \left(\frac{H^{\prime}\left(x_{0}+l\right)}{2 u H}\right)\right) d u .
\end{aligned}
$$


APPENDIX B

\section{TMR Liquid Water Content and Rain Flag}

A complete description of the TMR instrument and brightness temperature algorithm is given in Ruf et al. (1995), Janssen et al. (1995), and Keihm et al. (1995). Expressed in terms of kilometers on the ground seen at nadir from the TOPEX orbit, the half-power beamwidth is $43.4 \mathrm{~km}$ at $18 \mathrm{GHz}, 36.4 \mathrm{~km}$ at $21 \mathrm{GHz}$, and 22.9 $\mathrm{km}$ at $37 \mathrm{GHz}$, whereas the effective altimeter footprint diameter is on the order of $3 \mathrm{~km}$ (TOPEX 1989). Since the three channels may not integrate the same atmospheric patterns, ground processing partly solves the problem by averaging along-track brightness temperatures (TOPEX 1992). The rain flag, given in the merged TOPEX/Poseidon products, is based on an algorithm for detecting excess liquid water in the atmosphere (AVISO 1992). The atmospheric liquid water content $L_{z}(\mathrm{~mm})$ is calculated from the TMR brightness temperatures $T_{B}$ at 18, 21, and $37 \mathrm{GHz}$ (Keihm et al. 1995; S. Keihm 1995, personal communication), using the following relationship:

$$
\begin{aligned}
L_{z}= & (A+B) \times 10^{-3} \\
A= & -2280.4-12.241 T_{B_{18}}-5.128 T_{B_{21}} \\
& +28.964 T_{B_{37}} .
\end{aligned}
$$

If $A>600$, then

$$
B=0.43(A-600)+0.0003(A-600)^{2} .
$$

Otherwise, when $A<600, B=0$.

\section{REFERENCES}

Atlas, D., 1994: Footprints of storms on the sea: A view from spaceborne synthetic radar. J. Geophys. Res., 99, 7961-7969.

AVISO, 1992: Aviso User Handbook: AVI-NT-02-101-CN, Edition 2.1. Merged Topex/Poseidon Products, 213 pp.

Barrick, D. E., 1972: Remote sensing of sea state by radar. Remote Sensing of the Troposphere, V. E. Derr, Ed., U.S. Govt. Printing Office, 12.1-12.46.

— , and B. J. Lipa, 1985: Analysis and interpretation of altimeter sea echo. Advances in Geophysics, Vol. 27, Academic Press, 61100.

Capsoni, C., F. Fedi, C. Magistroni, A. Paraboni, and A. Pawlina, 1987: Data and theory for a new model of the horizontal structure of rain cells for propagation application. Radio. Sci., 22, 395404.

Chelton, D. B., and P. J. McCabe, 1985: A review of satellite altimeter measurements of sea surface wind speed with a proposed new algorithm. J. Geophys. Res., 90, 4707-4720.

Djuric, D., 1994: Weather Analysis. Prentice-Hall, 304 pp.

Goldhirsh, J., 1983: Rain cell size statistics as a function of rain rate for attenuation modeling. IEEE Trans. Antennas Propag., AP31, 799-801.

_ 1988: Analysis of algorithms for retrieval of rain rate profiles from a spaceborne dual-wavelength radar. IEEE Trans. Geosci. Remote Sens., 26, 98-114.

— , and I. Katz, 1979: Useful experimental results for earth-satellite rain attenuation modeling. IEEE Trans. Antennas Propag., AP27, 413-415.

— , and J. R. Rowland, 1982: A tutorial assessment of atmospheric height uncertainties for high-precision satellite altimeter missions to monitor ocean currents. IEEE Trans. Geosci. Remote Sens., GE-20, 418-434.

-, and E. J. Walsh, 1982: Rain measurements from space using a modified Seasat-type radar altimeter. IEEE Trans. Antennas Propag., AP-30, 726-733.

Guymer, T. H., G. D. Quartly, and M. A. Srokosz, 1995: The effect of rain on ERS-1 altimeter data. J. Atmos. Oceanic Technol., 12, $1229-1247$.

Hayne, G. S., D. W. Hancock, and C. L. Purdy, 1994: The corrections for significant wave height and attitude effects in the TOPEX/ Poseidon radar altimeter. J. Geophys. Res., 99, 24 941-24955.

Janssen, M. A., C. Ruf, and S. J. Keihm, 1995: TOPEX/Poseidon Microwave Radiometer (TMR): II Antenna pattern corrections and brightness temperature algorithm. IEEE Trans. Geosci. Remote Sens., 33, 138-146.

Keihm, S. J., M. A. Janssen, and C. Ruf, 1995: TOPEX/Poseidon Microwave Radiometer (TMR): III Wet troposphere range correction algorithm and prelaunch error budget. IEEE Trans. Geosci. Remote Sens., 33, 147-161.

Marshall, J. S., and W. M. Palmer, 1948: The distribution of rain drops with size. J. Meteor., 5, 165-166.

Marth, P. C., and Coauthors, 1993: Prelaunch performance of the NASA altimeter for the TOPEX/Poseidon project. IEEE Trans. Geosci. Remote Sens., 31, 315-332.

Monaldo, F. M., J. Goldhirsh, and E. J. Walsh, 1986: Altimeter height measurement error introduced by the presence of variable cloud and rain attenuation. J. Geophys. Res., 91, 2345-2350.

Morland, J. C., 1994: The effect of rain on TOPEX/Poseidon altimeter data. M.S. thesis, University College London and Document de Travail IFREMER, No. 94-03, 84 pp. [Available from IFREMER, BP 7029280 Plouzané, France.]

Nelder, J. A., and R. Meade, 1965: A simplex method for function minimization. Comput. J., 7, 308-313.

Olsen, R. L., D. V. Rogres, and D. B. Hodge, 1978: The $a R^{b}$ relation in the calculation of rain attenuation. IEEE Trans. Antennas Propag., AP-26, 318-329.

Petty, G. W., 1990: On the response of the SSM/I to the marine environment: Implication for atmospheric parameters retrievals. Ph.D. dissertation, University of Washington, $291 \mathrm{pp}$.

- 1995: Frequencies and characteristics of global oceanic precipitation from shipboard present-weather reports. Bull. Amer. Meteor. Soc., 76, 1593-1615.

_ servations calibrated against surface data during TAMEX. $J$. Appl. Meteor., 6, 489-505.

Quartly, G. D., T. H. Guymer, and M. A. Srokosz, 1996: The effects of rain on Topex radar altimeter data. J. Atmos. Oceanic Technol., 13, 1209-1229.

Ruf, C., S. J. Keihm, and M. A. Janssen, 1995: TOPEX/Poseidon Microwave Radiometer (TMR): I Instrument description and antenna temperature calibration. IEEE Trans. Geosci. Remote Sens., 33, 125-137.

SEASAT, 1979: Gulf of Alaska workshop Rep. Vol. I, Panel Rep. JPL Int. Rep. 622-107. [Available from Jet Propulsion Laboratory, 4800 Oak Grove Dr., Pasadena, CA 91109.]

Slack, J. K., A. R. Holt, and V. Brown, 1994: Implementation of direct algorithms. Rain radar retrieval algorithms. Final Rep. ESA Contract 101046/92/NL/GS, 440 pp. [Available from European Space Agency, ESTEC, P.O. Box 299, 2200 AG Nordwijk, the Netherlands.]

Szoke, E. J., E. J. Zipser, and D. P. Jorgensen, 1986: A radar study of convective cells in mesoscale systems in GTE. Part I: Vertical profiles statistics and comparison with hurricane. J. Atmos. Sci., 43, 182-197.

Testud, J., P. Amayenc, and M. Marzoug, 1992: Rainfall rate retrieval from a spaceborne radar: Comparison between single-frequency, dual-frequency, and dual-beam techniques. J. Atmos. Oceanic Technol., 9, 599-623.

_ — _ X. Xou, and T. Tani, 1996: Tests of rain profiling al- 
gorithms for a spaceborne radar using raincell models and real data precipitation fields. J. Atmos. Oceanic Technol., 13, 426453.

TOPEX, 1992: TOPEX ground system science algorithm specification. Rep. JPL TP. SP. 43-2738. JPL, Pasadena, CA. [Available from Jet Propulsion Laboratory, 4800 Oak Grove Dr., Pasadena, CA 91109.]

TOPEX Radar Altimeters Systems Specification, 1989: Wallops NASA/Goddard Space Flight Center, Greenbelt, MD. WFF-67285-004004, Rev. 6 Flight Facility Internal Publication.

Tournadre, J., and J. C. Morland, 1998: The effect of rain on TOPEX/ Poseidon altimeter data: A new rain flag based on $\mathrm{Ku}$ and $\mathrm{C}$ band backscatter coefficients. IEEE Trans. Geosci. Remote Sens., in press.
Ulaby, F. T., R. K. Moore, and A. K. Fung, 1981: Microwave Remote Sensing: Active and Passive, Vol. I, Addison-Wesley, 456 pp.

Walsh, E. J., F. M. Monaldo, and J. Goldhirsh, 1984: Rain and cloud effects on a satellite dual frequency radar altimeter operating at 13.5 GHz and $35 \mathrm{GHz}$. IEEE Trans. Geosci. Remote Sens., GE22, 615-622.

Zieger, A. R., D. W. Hancock, G. S. Hayne, and C. L. Purdy, 1991: NASA radar altimeter for the TOPEX/Poseidon project. Proc. IEEE, 79, 810-826.

Zipser, E. J., and K. R. Lutz, 1994: The vertical profile of radar reflectivity of convective cells: A strong indicator of storm intensity and lightning probability. Mon. Wea. Rev., 122, 17511759. 